\title{
Small Artery Remodeling: Current Concepts and Questions
}

\author{
Jeroen van den Akker Marieke J.C. Schoorl Erik N.T.P. Bakker Ed vanBavel \\ Department of Biomedical Engineering and Physics, Academic Medical Center, University of Amsterdam, \\ Amsterdam, The Netherlands
}

\section{Key Words}

Actin - Artery - Biomechanics - Collagen - Elastin ·

Hypertension $\cdot$ Inflammation $\cdot$ Remodeling $\cdot$ Smooth

muscle cell $\cdot$ Vasoconstriction

\begin{abstract}
Blood flow regulation by small arteries and arterioles includes adaptation of both vascular tone and structure. It is becoming clear that tone and remodeling of resistance vessels are highly interrelated. Indeed, concepts pointing to continuous resistance artery adaptation and plasticity are emerging. The purpose of this review is to summarize such concepts and approaches related to vascular organization and remodeling, and to point out the missing links and possible directions for future research. We focus on the individual vessel level. Since several relevant studies are based on isolated vessels, we briefly re-iterate the available isobaric and isometric approaches. We further discuss the major elements of the small artery wall and their relation to the passive and active mechanical properties, as important determinants for vascular remodeling. The cytoskeletal elements and actin re-organization during remodeling are discussed, as well as the re-lengthening of smooth muscle cells during prolonged constriction. We then consider tone as major causal factors in remodeling and discuss the role of vessel wall inflammation. Finally, we illustrate examples of current quantitative, integrative approaches of small artery mecha-
\end{abstract}

nosensing and adaptation that may lead to a physiomics description of small artery adaptation in health and in diseases such as hypertension.

Copyright $\odot 2009$ S. Karger AG, Basel

\section{Introduction}

Resistance vessels are the small arteries and arterioles that regulate local perfusion and organ resistance. These typically include vessels of around $200 \mu \mathrm{m}$ or smaller in diameter [1]. Flow regulation by these vessels occurs at time scales from seconds to weeks, involving adaptation of luminal diameter by both vascular tone and vascular

Previous articles in this special topic series: 1. Pohl U, Meininger G: Editorial. J Vasc Res 2009;45:503. 2. Hudlicka O, Brown MD: Adaptation of skeletal muscle microvasculature to increased or decreased blood flow: role of shear stress, nitric oxide and vascular endothelial growth factor. J Vasc Res 2009;46:504-512. 3. Krenzt AJ, Clough G, Byrne CD: Vascular disease in the metabolic syndrome: do we need to target the microcirculation to treat large vessel disease? J Vasc Res 2009;46:515-526. 4. Sen CK, Gordillo GM, Khanna S, Roy S: Micromanaging vascular biology: tiny microRNAs play big band. J Vasc Res 2009;46:527-540. 5. Orr AW, Hastings NE, Blackman BR, Wamhoff BR: Complex regulation and function of the inflammatory smooth muscle cell phenotype in atherosclerosis. J Vasc Res 2010;47:168180.

\section{KARGER}

Fax +4161306 1234 E-Mail karger@karger.ch www.karger.com
(C) 2009 S. Karger AG, Basel

1018-1172/10/0473-0183\$26.00/0

Accessible online at:

www.karger.com/jvr
Prof. Dr. Ed van Bavel

Department of Biomedical Engineering and Physics

Academic Medical Center L0-120

PO Box 22660, NL-1100 DD, Amsterdam (The Netherlands)

Tel. +31 20566 5203/566 5200, Fax +31 20691 7233, E-Mail e.vanbavel@amc.uva.nl 
structure. This occurs in response to a wide variety of local mechanical and biochemical stimuli as well as endocrine and neural influences. Flow regulation malfunctions in a variety of cardiovascular and metabolic pathologies.Examplesincludeimpairedendothelium-dependent dilation under oxidative stress and inward remodeling of resistance vessels in various hypertensive disorders. Furthermore, resistance vessels may adapt to the presence of flow-limiting stenoses in proximal vessels [2].

The notions that vascular caliber regulation involves multiple stimuli (e.g. wall tension [3], shear stress, metabolic factors $[4,5]$ ) in a complex mechanical setting, widely diverging time scales and a distributed resistance network spanning many generations raises several fundamental questions: how do blood vessels combine responses to pressure, flow, metabolic factors? In a remodeling vessel, how do functional characteristics such as the capacity for active tension generation change? If flow can be controlled by either tone or remodeling, what then determines their balance, i.e. how does a vessel 'choose' between deep tone and a wide structural caliber or shallow tone and a narrow caliber? Eventually, an integrative 'physiomics' approach could answer such questions. Such an approach would simultaneously consider the mechanical regime, various control loops (e.g. regulation based on wall tension and shear stress), different time domains (tone and remodeling), and the spatial organization of resistance vessels in networks, and ultimately would provide a detailed 4-dimensional multiscale approach to caliber regulation. Such an approach is not yet available, but might evolve from several useful initiatives. Accordingly, the purpose of this review is to summarize current concepts and approaches related to vascular organization and remodeling, and to point out the missing links and possible directions for future research.

We focus on the individual vessel level and on wall plasticity and eutrophic remodeling, i.e. in the absence of a change in wall cross-sectional area, ignoring proliferation and apoptosis in the vascular wall [6]. Since several relevant studies are based on isolated vessels, we briefly re-iterate the classic experimental approaches, isometric wire-mounted and isobaric cannulated vessel segments. We further discuss the major elements of the small artery wall and their relation to the passive and active mechanical properties, as important determinants for vascular remodeling. We then consider cytoskeletal events and tone as major causal factors in remodeling, and discuss the role of vessel wall inflammation. Finally, we illustrate examples of current quantitative, integrative approaches of small artery adaptation.

\section{Isolated Small Artery Techniques}

The contractile properties of intact small arteries are generally studied by either of 2 methods [7]. Segments can be mounted in a wire myograph, where force development is measured at a certain, constant, internal circumference (isometric conditions). Alternatively, vessels are cannulated in a pressure myograph and diameter is measured while pressure is controlled (isobaric measurements).

\section{Wire Myograph}

The wire myograph was first described by Mulvany and Halpern in 1976 [8], and was based on method originally proposed by Bevan and Osher 4 years earlier [9]. This setup is now widely used in routine vascular physiology and pharmacology. In an isometric wire myograph, vessel segments are mounted as ring preparations on 2 wires, one of which is connected to a force transducer. The other wire is attached to a micrometer, thereby allowing precise control of vascular circumference. An equivalent radius ( $\mathrm{r}$ ) can be calculated from this circumference, although it should be realized that there is substantial deformation from the normal circular shape. Tension (i.e. force per length) is recorded and based on the presumed parallel arrangement of smooth muscle cells (SMC) and extracellular matrix; active tension is calculated from the difference between recorded tension and the passive component obtained during full dilation. After mounting, the vessels are 'normalized', i.e. set to the optimal radius for active tension. While this would ideally involve establishment of the full active radius-tension relation, the practical solution is to base the normalization on the passive radius-tension relationship of the vessel $[10,11]$. First, the passive radius at an equivalent pressure of $100 \mathrm{~mm} \mathrm{Hg}\left(\mathrm{r}_{100}\right)$ is determined from the interception of an exponential fit of the radius-tension relation and the Laplace relation $(\mathrm{T}=\mathrm{P} \cdot \mathrm{r})$ at $100 \mathrm{~mm} \mathrm{Hg}[10]$. The distension is then usually set to $0.9 \cdot \mathrm{r}_{100}$, since active force production of the vessel is postulated to be maximal at this strain, and kept constant during the experiment. This normalization is based on the frequently used rat mesenteric small arteries. It is not clear whether this would also reflect the optimum for force development in other vessels. For the bulk of studies, this is not relevant, as long as sufficient active tension can be recorded on top of a low passive tension. However, as we explain below, the active radius-tension relation is dynamic, while the passive relationship also changes during remodeling. Therefore, we would suggest including detailed registra- 
tion of both relations in studies on remodeled vessels, but also in studies that address mechanosensing, or those that explicitly compare maximal active tensions between groups.

\section{Pressurized Vessels}

In 1966, Burg et al. [12] published a technique for the investigation of isolated, pressurized renal tubuli. This method, in which the wall is vacuum-clamped between 2 double-barreled pipettes, was adapted by the lab of Duling for arterioles [13], and still seems the approach of choice for cannulating the tiniest arterioles. This technique, as well as an alternative double-barreled technique [14], require complex cannula construction, and a more general approach is the cannulation by 2 single-barreled pipettes and suturing [15]. Pressures are generated by hydrostatic height, by roller pumps with pressure feedback, or by electric-pneumatic converters. Diameters are measured manually, using video calipers or off-line analysis of video images, or automatically, using a variety of diameter tracking algorithms [16].

An extensive 'normalization' protocol such as for wiremounted vessels is not needed. Rather, the vessel is set to the (assumed) normal pressure, and the passive diameter is recorded, allowing for normalization of subsequent diameter recordings. Studies that include mechanosensing or remodeled vessels almost always include the pressurediameter relation of the relaxed vessel in order to quantitate the mechanical properties and delineate the span of possible diameters. Axial stretch of cannulated vessels seems less standardized, and this issue seems somewhat ignored. In vivo, vessels are under axial strain due to tethering to the surrounding tissue and the longitudinal stress resulting from the pressure. Vessels thus retract considerably upon isolation. Ideally, one should set the vessel back to its in vivo length. Yet, this is difficult to determine, if it is at all constant. Usually, cannulated vessels are straightened at a standardized pressure. However, this remains a relatively coarse method. Setups including recording of the axial tension are available, possibly allowing better standardization.

There are many reasons for choosing either of the above techniques. Amongst these, the wires allow generally faster mounting and multiple parallel segments, are forgiving with respect to small side branches, and allow easier and much faster data collection. Moreover, the isometric protocols are relatively well standardized. The cannulas provide more realistic mechanical loading and allow the study of flow. Furthermore, spontaneous basal tone and myogenic responses are more easily induced in pressurized vessels. In general, while pharmacological and physiological studies might employ respectively the wires and cannulas, both techniques have been shown to be useful for the understanding of tone control as well as vascular plasticity, as will be explained below.

\section{Small Artery Matrix and Passive Mechanical Properties}

The organization of blood vessels in 3 layers (intima, media, adventitia) was described in detail by Rhodin in the Handbook of Physiology [17]. Figure 1 provides TEM photographs of a mesenteric resistance vessel, showing these layers and their major components. The major components believed to determine the mechanical properties in passive vessels, and thereby the caliber of the vessel, are elastin and collagen. It leaves no doubt that remodeling requires reorganization of at least these components. We therefore discuss their structure, synthesis and embedding, cross-linking and degradation in relation to the mechanical properties of the passive vessel.

\section{Elastin}

In large vessels, the large amount of elastin (e.g. 111 $\mathrm{mg} / \mathrm{g}$ wet weight in the rat carotid artery [18]) functions to dampen pressure pulsations [19]. Elastin content decreases towards smaller vessels but, despite the 'muscular' appearance of the vessels, is still abundant (e.g. 15 $\mathrm{mg} / \mathrm{g}$ in small mesenteric arteries [19]). This is reflected by the volume occupied by elastic matrix, around $50 \%$ in the aorta and $14 \%$ in the superior mesenteric arteries. In arterioles, elastin is restricted to the internal elastic lamina. This sheet-like structure is built up by intertwined elastic fibers. Based on electron microscopy, thickness of the internal elastic lamina is in the order of $1 \mu \mathrm{m}$ [20]. In somewhat larger resistance vessels, an external elastic media may still be present, as well as some elastic fibers between the SMC [19].

Elastin is produced mainly by SMC, although endothelial cells and adventitial fibroblasts are also capable of synthesis of tropoelastin [21,22]. Elastic fibers consist of a core of globular tropoelastin monomers joined by desmosine cross-links $[23,24]$. The core of each fiber is surrounded by a sheet of unbranched microfibrils of 10-12 $\mathrm{nm}$ in diameter $[25,26]$, containing fibrillins as well as an array of other macromolecules.

The incorporation of tropoelastin into elastic fibers is based on self-assembly and ordering (coacervation) and cross-linking. In vivo, the coacervation process is guided 

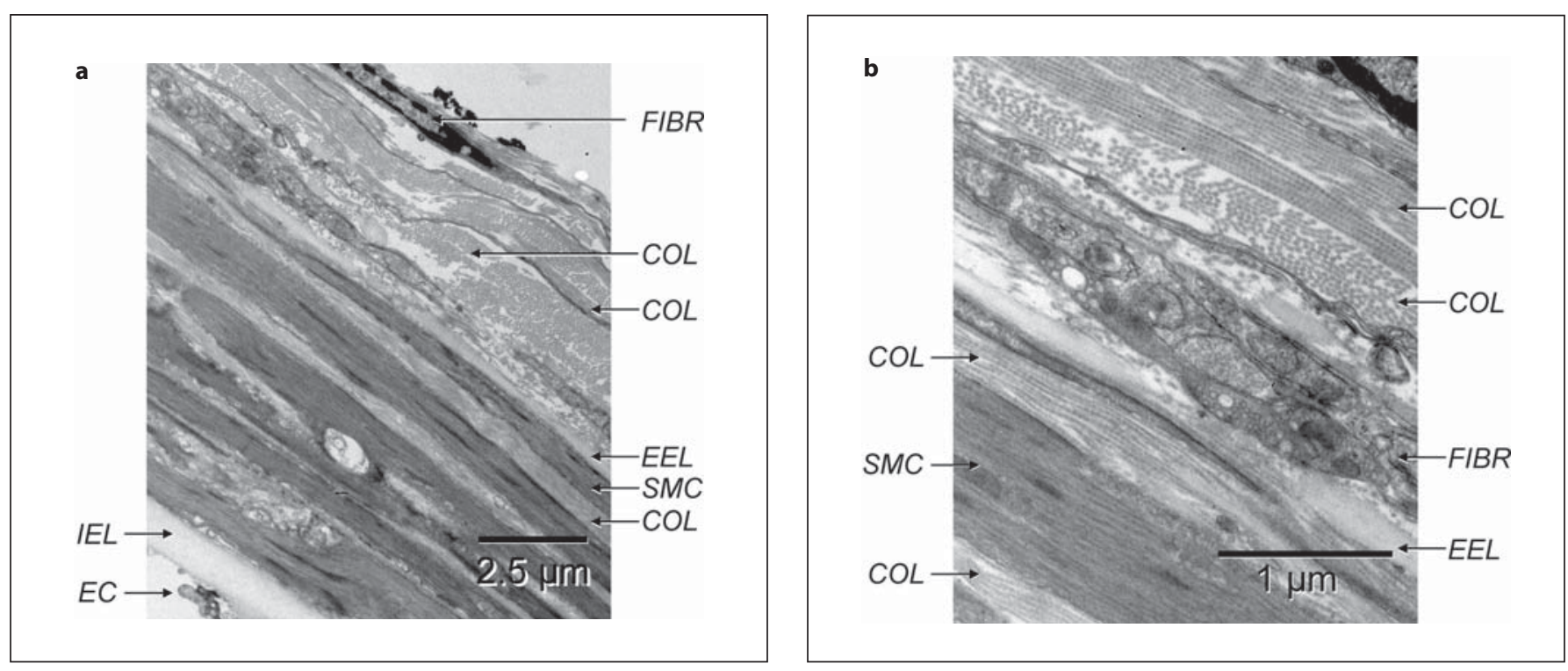

Fig. 1. a Transmission electron microscopic image of a rat mesenteric small artery fixed at $100 \mathrm{~mm} \mathrm{Hg}$ equivalent pressure. $\mathbf{b}$ Detail of the media and adventitia. $\mathrm{EC}=$ Endothelial cell; IEL = internal elastic lamina; EEL = external elastic lamina; $\mathrm{COL}=$ collagen; $\mathrm{SMC}=$ smooth muscle cell; FIBR = fibroblast.

by fibrillin. Thus, formation of elastic fibers and sheets starts with the assembly of fibrillin molecules at the cell surface [27] due to transglutaminase-induced cross-linking of fibrillin-1 monomers and microfibril-associated glycoproteins in the interbead filaments $[28,29]$. These microfibrils form parallel bundles that may be stabilized at inter-microfibrillar regions and serve as scaffolds for deposition of tropoelastin. The resulting elastin is stabilized by lysyl oxidase-derived desmosine cross-links. This process is facilitated by fibulins 4 and $5[21,30]$.

Elastin, once formed by cross-linking, is a remarkably stable protein in the absence of pathologies. Yet maintenance is required to regulate the local amount of elastic fibers and their physical properties. In particular, remodeling of resistance vessels requires that the internal elastic lamina is also restructured, by a combination of incorporation of new tropoelastin molecules into the existing layer, degradation of part of the layer, and formation and degradation of intra- and intermolecular cross-links. We established a role for transglutaminases in small-artery eutrophic inward remodeling [31]. While these enzymes are involved in the genesis of elastin fibers, there is currently no evidence that they cross-link mature elastin.

As the name indicates, elastic fibers can easily be distended, to around twice their resting length [32]. Moreover, the incremental elastic modulus (i.e. the slope of the stress-strain relation) is essentially constant over a large part of this range, and is in the order of $600 \mathrm{kPa}$. The structural base for elastin elasticity is extremely complex and is the subject of ongoing discussions [26, 33-35]. Extension of the tropoelastin monomers forms the base of the elasticity of elastin. This extension is based on uncoiling of large dynamic hydrophobic regions. Upon stretch, tropoelastin becomes more ordered, or entropy becomes less, and indeed the elastic nature of elastin is of entropic origin [36]. Hydration of tropoelastin and the presence of bulk water filling the space between the tropoelastin molecules is crucial; without water, elastin is brittle [34]. Various tropoelastin isoforms exist due to alternative splicing [36-38]. Fundamental elastic properties of these isoforms apart from resting length of the tropoelastin molecule are probably not very different if alternative splicing occurs in the hydrophobic regions, but in other regions this could affect the number of cross-linking sites [34] and thereby affect the degree of cross-linking and the final architecture and stability of the elastin molecule.

\section{Collagen}

Like elastin, collagen content also decreases in smaller vessels (e.g. from $124 \mathrm{mg} / \mathrm{g}$ in carotid arteries [18] to 67 $\mathrm{mg} / \mathrm{g}$ in mesenteric vessels [19]). Within small artery networks, collagen content decreases further towards the periphery, e.g. from 20 to $9 \%$ of the wall volume over the mesenteric bed [39]. In small arteries, the non-fibrillar 
collagen IV forms the basement membrane, while collagen I and III are present in an irregular network of small fibrils in the media and in large amounts in the adventitia. Collagen organization and biomechanics in small arteries need more extensive investigation; the information below is therefore mainly derived from tendons, while some studies address collagen in the major arteries.

Collagen is assembled in a multistep-process with distinct steps at specific locations inside the cell and in the extracellular space. The base of the collagen hierarchical organization is formed by the single polypeptide, the central part of which folds into a tight, right-handed $\alpha$-helix [40]. Three polypeptides form a left-handed triple helix with a pitch of around $10.4 \mathrm{~nm}$. Collagen type I is a heterotrimer made up of two $\alpha_{1}(\mathrm{I})$ and one $\alpha_{2}(\mathrm{I})$ peptide; collagen type III is a homotrimer containing $\alpha_{1}$ (III). In a so-called D staggered array, $280 \mathrm{~nm}$ long trimers are packed into microfibrils at an offset of $67 \mathrm{~nm}$, generating the characteristic striation in fibrillar collagen seen in EM [41]. A wide variety of models for microfibrillar organization has been described [40], most of them based on a thickness of 5 or more collagen trimers. In tendon collagen I, five-molecule microfibrils are organized in a regular pattern, with individual collagen trimers traversing between microfibrils [42]. This networked rope design adds to the strength of collagen. Many such microfibrils form fibrils. The fibrils finally form fibers and sheets via interfibrillar proteoglycans [43]. The EM images in figure 1 indicates that the 'fibers' in the media of this resistance vessel have only a few fibrils, while some fibrils can be seen in the adventitia that follow the same path and therefore could be considered to form a fiber. The final intra- and inter-molecular cross-linking within the ECM is mediated by lysyl oxidase [44].

Two proteolytic systems are responsible for the degradation of many of the ECM components, including collagen. The fibrinolytic plasminogen activation system degrades laminin and fibronectin directly $[45,46]$. Elastin and collagen are degraded by matrix metalloproteinases, some of which can be activated by plasminogen [22, $44,46,47]$. It is possible that, a part of the collagen aggregates is internalized by fibroblasts after an initial extracellular proteolytic event. There, urokinase plasminogen activator receptor associated protein may cause a further degradation of collagen, although this mechanism is still under debate [46].

The stress-strain curve of collagen could be based on deformation at many possible levels of integration, ranging from stretch of the individual triple helices to straightening of the complete fibrils, which are known to follow a wavy pattern in the vascular wall (fig. 1), and deformation of the interfibrillar connections. Understanding the organizational level at which deformation occurs could provide insight into the link between changes in molecular organization, such as cross-linking, and alterations of the pressure-diameter relation of the blood vessel. The basis for the deformation of collagen has been extensively studied in tendons $[48,49-52]$. The stress-strain curve is characterized by a first region of low stress where macroscopic straightening occurs. This is followed by a 'heel' region where stiffness rapidly increases and where the lateral order of the collagen molecules increases (believed to be caused by a straightening of kinked molecules [49]), and a linear part with high stiffness. Above 5\% strain, stiffness falls again due to irreversible changes. In the linear part, the axial D period (see above) increases with stress. Sasaki and Odajima [53] found fibrillar strain to parallel tissue strain, and estimated a fibrillar stiffness of $430 \mathrm{MPa}$, but Puxkandl et al. [50] observed that only 10$20 \%$ of the tendon strain is associated with strain of the fibrils for slow strain rates. The remaining strain may stem from deformation of the proteoglycan-rich matrix connecting the fibrils. In biaxially loaded bovine pericardium, Liao et al. [54] observed that fibrillar strain only started to occur at $20 \%$ macroscopic strain, attributed to straightening of the fibers, and above that accounted for only $32 \%$ of the strain, the remaining strain was attributed to inter-fibrillar slippage and heterogeneous straightening lengths of the fibrils. In similar experiments on porcine mitral valves, fibrillar strain only occurred at the end of the non-linear region of the stress-strain curve [55]. The stiffness of the fibrils was estimated to be $\sim 100$ $\mathrm{MPa}$, as compared to the macroscopic stiffness of 3.5 $\mathrm{MPa}$. These differences were explained on the basis of orientation and alignment of the fibrils. Fibril strain in human aortic adventitia was only $1 \%$ for macroscopic strains of $16 \%$; the curvilinear macroscopic stress-strain curve was explained by fiber straightening, fiber reorientation, and finally fiber strain [56].

The above findings leave little room for a role of collagen fibril extension in small artery mechanics at relevant blood pressures. Rather, fibrils are expected to remain at rather constant length and straighten towards a less wavy structure during vessel distension. While the waviness indicated in figure 1 suggests room for straightening, possible intrafibrillar cross-linking and attachment to the ground substance may still provide substantial stiffness to these fibers. A further quantitation of collagen architecture in distended vessels will be needed to test whether this is indeed the case. In addition, local vis- 


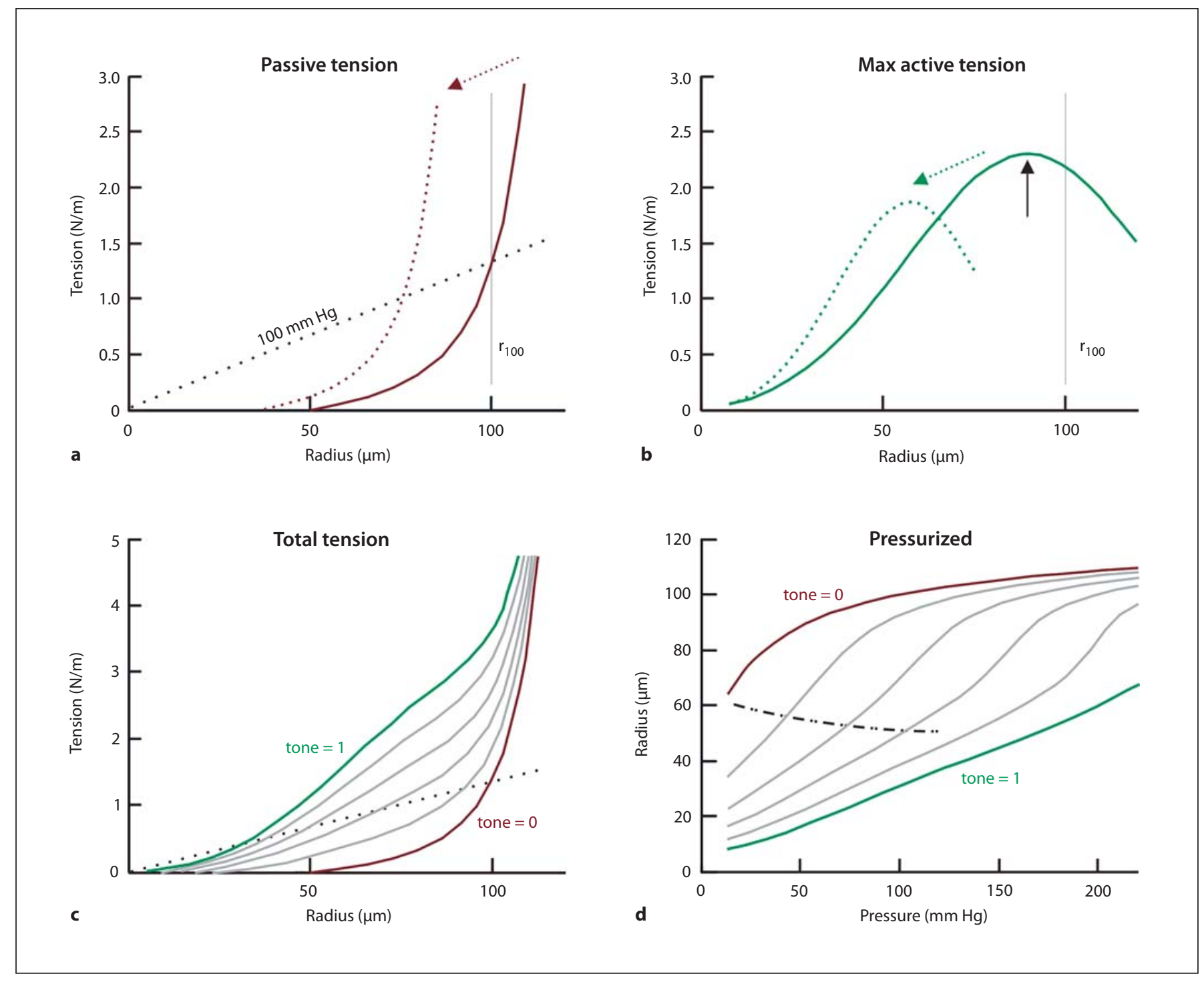

Fig. 2. Schematic drawing of radius-tension and pressure-radius relations. a Passive relation (solid brown). The dashed line indicates the $100 \mathrm{~mm} \mathrm{Hg}$ isobar on the basis of the Laplace relationship. The passive radius at $100 \mathrm{~mm} \mathrm{Hg}$ is indicated as $\mathrm{r}_{100}$. Inward remodeling is reflected by a leftward shift of this curve (dotted brown curve and arrow). b Active radius-tension relation under full activation (solid green), demonstrating a maximum at $0.9 \mathrm{r}_{100}$ (solid arrow). SMC reorganization would shift this curve (dotted green curve and arrow). $\mathbf{c}$ Total tension for tone $=0$ (brown) to 1 (green); intermediate tone levels are indicated in grey. Intercepts with the dashed isobar indicate the radii at $100 \mathrm{~mm} \mathrm{Hg}$ for various tone levels. $\mathbf{d}$ Conversion of the relations in $\mathbf{c}$ to pressure-radius relations. The dash-dot line indicates an increase in tone with pressure (myogenic response), required to stabilize the vascular radius. co-elastic properties of collagen could be determined. A possible strategy is based on microrheology [57] of beads bound to the collagen using antibodies.

\section{Matrix Organization and Mechanical Properties of the Passive Wall}

Figure 2a depicts a schematic radius-tension relation of a small artery during maximal vasodilation, as would be measured in wire myography. The active curves in figure $2 \mathrm{~b}$ and $\mathrm{c}$ will be discussed below. Figure $2 \mathrm{~d}$ ('tone $=$ 0 ') shows the passive characteristics in a cannulated vessel. Ignoring finite wall thickness and axial distension, passive curves recorded using isometric and isobaric methods are roughly equivalent, and these curves can be converted into each other via the law of Laplace [58-63]. The passive vessels are characterized by an unloaded di- 
Fig. 3. The hook-on model (a) and serial elements model (b) both explain the nonlinear passive radius-tension curve (c). In the hook-on model, the vessel is represented by a parallel arrangement of elastin and collagen springs. Increasing tension induces distension (grey area) and thereby a recruitment of collagen springs, raising the vessel stiffness. In the serial elements model, collagen is not a spring but a string that can bend but cannot be extended. Each element is an elastin spring in parallel to several such strings. The vessel wall is represented by many of such elements in series. Upon ongoing tension, the elements become rigid one by one, also leading to a non-linear radius-tension relation. $\mathbf{a}$ and $\mathbf{b}$ are modified from [72], which also gives a detailed mathematical analysis and experimental test of both models.

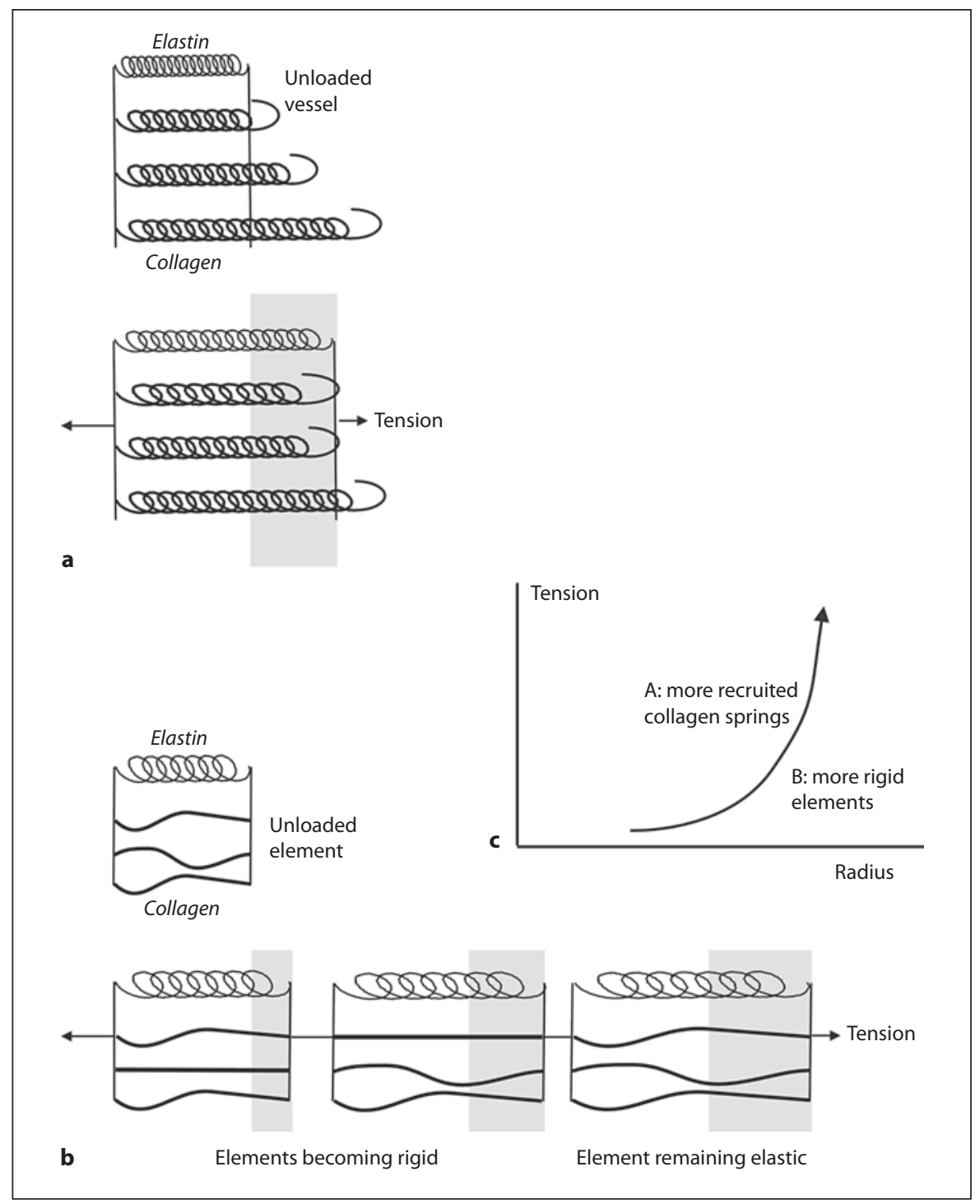

ameter and non-linear elasticity reflected by an increasing incremental elastic modulus at higher distensions. This non-linearity is reflected in the wire myographbased curves and the stabilization of passive diameter at increasing pressures. Physiologically relevant matrix remodeling is reflected by a change of these curves. Thus, in figure $2 \mathrm{a}$, the dotted arrow and grey relation show an inwardly remodeled vessel.

The shape of the passive curves is generally believed to depend on the contribution of elastin and collagen [13, $64,65]$, dominated at low strain by elastin, having a low elastic modulus $(\sim 0.4 \mathrm{MPa})$. At higher strains, the stiff ( $\sim 100-1,000 \mathrm{MPa})$ collagen fibers start to hook on, causing a rapid increase in stress. This 'hook on model' (fig. 3a) was originally developed for large vessels [6668]. The organization of the mesenteric arterial wall was investigated by scanning electron microscopy in vessels fixed in either relaxed or contracted conditions. Collagen, elastin and cells were selectively degraded in order to inspect the individual components at a more detailed level. This revealed a pericellular network consisting of irregular collagen fibrils in a network of fibrous elastin [39]. Elastase increased the diameter of cannulated mesenteric vessels, especially at low pressures, but also over the entire pressure range in mesenteric arteries of hypertensive rats [69].

There are concerns with the hook-on model and its relevance for resistance vessels. Thus, in this 1-dimen- 
sional model, ongoing recruitment of only small fractions of the collagen fibers is needed to explain the gradual stiffening at higher distensions. Final recruitment at the highest pressures can be estimated to be $5-6 \%$ [70, $71]$. It seems not realistic that $95 \%$ of the collagen is not involved in the mechanics of the wall at all. Moreover, the fibers that are first recruited will be distended by substantial amounts by the time the vessel has reached its maximal diameter. This is at variance with the strain limit of 3-4\% where collagen fibers are known to break [72]. A final concern relates to remodeling: in a theoretical analysis we showed that outward remodeling in the hook-on model requires breakdown of nearly all of the collagen [72], followed by deposition of new collagen at larger hook-on diameters. In this transition, the vessels would be very vulnerable for mechanical overload. Moreover, there is no histological evidence for such massive degradation of collagen in outward remodeling. We formulated an alternative 1-dimensional conceptual model of vascular wall mechanics (fig. $3 b$ ) that is based on infinite stiffness of collagen fibers. In this model, elements are arranged in series. Each element has a linear elastin spring and a number of collagen strings, the shortest of which determines the maximal distension of that element. The 3-parameter model (elastin stiffness and 2 parameters for distribution of collagen string length) could be fitted to experimental stress-strain curves, obtained on wire-mounted rat mesenteric small arteries. Moreover, the model predicts gradual outward remodeling following collagen degradation, and these predictions could be confirmed by collagenase experiments [72].

While the 1-dimensional models provide biomechanical concepts, they are clearly oversimplifying. More detailed 2-or 3-dimensional models and possibly finite element approaches will be required to quantitate the structural base of vascular biomechanics. Such work has mainly been performed for large vessels, but, provided sufficient anatomical information is available, could also be applied for the understanding of structural remodeling of resistance vessels. The models are generally based on constitutive equations that account for the biomechanical properties of relevant wall structures. The fundaments of such approaches can be found in the work of Fung [32]. Most models treat the vessel wall as a structural continuum, in which relations are defined between normal and shear stresses and strains on the basis of a mathematical matrix of material properties such as Young's and shear moduli.

Local stresses may remain in vessels under zero external load. Such residual stresses reduce the stress gradients across the vessel wall under normal load, providing a suitable mechanical environment for SMC contractile function [73]. Residual stresses are of interest for remodeling, since on one hand they are likely to influence local cell behavior, and on the other hand local remodeling processes would underlie the development of residual stresses. Their study could thus provide further insight into vascular plasticity. Elastin appears to have an important role in stress distribution. Enzymatic digestion of elastin, but not collagen digestion or SMC destruction, was shown to reduce residual stress [74]. The circumferential component of residual strain is characterized by the opening angle following axial cutting of the vessel. This angle was shown to correlate well with the mediato-lumen ratio. In a biomechanical model, smooth muscle contraction is predicted to cause an increase in opening angle, while relaxation results in a decrease [75]. In general, the opening angle decreases towards the periphery.

\section{Smooth Muscle Cells and Mechanical Properties of Small Arteries}

\section{Smooth Muscle Cells}

SMC content in the media increases with decreasing diameter, up to $85 \%$ in small arteries [18]. Unlike in large vessels, SMCs in most small arteries and arterioles are aligned preferentially circumferentially, with a typical pitch angle smaller than $2^{\circ}$. This configuration has been suggested to provide an optimal resistance against vessel distension [18, 76-78]. The small angle would create a better overlap between cell tips, thereby creating a helical turn of SMCs in the vessel wall [79]. Considering the current interest in vascular plasticity and re-lengthening of SMC during activation, the normal length of SMC along the resistance vessel tree in the various organs also becomes relevant. McGrath et al. [79] indicate lengths of around $100 \mu \mathrm{m}$, allowing the SMC in small arterioles to completely wrap the vessel lumen. Haas and Duling [80] quantitated the dimensions of vascular cells in various microvascular beds and report SMC length of around 65 $\mu \mathrm{m}$ in dilated rat pial and hamster cheek pouch arterioles of 80-100 $\mu \mathrm{m}$ diameter. Miller et al. [81] report SMC length in rat intestinal arterioles to be $80-90 \mu \mathrm{m}$, essentially independent of vessel diameter in the range between 24 and $62 \mu \mathrm{m}$ arterioles. A single SMC could thus cover the full circumference in small arterioles, but not larger resistance vessels. Although more complex shapes are found in branches and in the precapillary arterioles 
$[82,83]$, it seems fair to generalize that small artery SMC are spindle-shaped, with a length of 60-100 $\mu \mathrm{m}$ that does not depend on the branching order, and a small pitch.

The dense focal adhesions at the membrane and cytosolic dense bodies may be considered to form the mechanical base of the SMC. Various actin isoforms span these anchoring points, forming the actin cytoskeleton. Other actins interact with myosin during contractile force development, forming contractile elements analogous to sarcomeres [84], but with a side-polar rather than bi-polar arrangement, allowing a larger range of shortening. Intermediate filaments surround these structures, while microtubules act as rigid though dynamic struts. We discuss the role of these elements in force development and maintenance of cell organization during activation and remodeling. In addition to studies on small arteries, we include some findings and concepts from non-vascular SMC that may be relevant for the resistance vessels too.

Stimulus-contraction coupling, contractile element signaling and interaction of actin and myosin during contractile activation of smooth muscle have been well reviewed [85-88]. A common finding is that calcium-dependent activation is followed by calcium sensitization, i.e. myosin light-chain phosphorylation at low levels of intracellular calcium, and subsequent maintenance of force in the absence of myosin light-chain phosphorylation, allowing the maintenance of intermediate and chronic force at low energy expenditure. Latch bridges, i.e. non-cycling actomyosin bonds in the absence of myosin light-chain phosphorylation might explain the state of chronic tension and low energy expenditure of SMC [89]. While it remains unclear whether such bridges exist in small arteries, the concept has recently been used for modeling small artery contraction [90]. Alternatively, recent work on SMC makes clear that both myosin and actin fibers, as well as other intracellular fibers and cytoskeletal elements, form dynamic structures in SMC, whose dynamic organization may underlie adaptation to maintained activation and remodeling.

In a series of studies mainly on airway SMC, Seow and coworkers provide evidence that the contractile apparatus adapts to SMC load. Thus, new 'sarcomeres' are formed in series upon maintained lengthening of the cell, causing an extensive broadening of the active length-tension relation (see [91]). Rapid evanescence of myosin filaments and stabilization of the filaments by myosin lightchain phosphorylation underlie this process. Whether such myosin polymerization also occurs in blood vessels, is unknown. Increased actin polymerization has been found during SMC contraction, and is indeed considered essential for such contraction [92]. Recently, Chen et al. [93] demonstrated that myosin phosphorylation triggers such polymerization in rat mesenteric small arteries, indicating that the polymerization concerns the 'contractile element' rather than 'cytoskeletal' actin. Such polymerization may alternatively reflect longer actin, more parallel actin, or the recruitment of cytoskeletal actin to the contractile apparatus. These possibilities remain to be investigated, e.g. on the basis of altered active forcelength relationships.

This dynamic organization of the actin cytoskeleton seems to be of primary importance for maintained tone and vascular plasticity. Gunst and Zhang [94] provide a paradigm for the regulation of SMC contraction that could be valid for small arteries too: a tightly regulated polymerization of globular G-actin to fibrillar F-actin is required for tension generation of SMC. Such polymerization does not regulate the cross-bridge cycling, but rather forms an independent process that provides stabilization of the cytoskeleton. The polymerization seems to occur mainly in a submembranous area of the SMC, providing membrane rigidity and adaptation to local forces acting on the dense focal adhesions. It remains to be established whether polymerization occurs also at the actin fibers that interact with myosin. The focal adhesion junctions are not static structures. Rather, contractile stimulation recruits structural proteins such as $\alpha$-actinin and vinculin that connect actin filaments to these junctions. Both actin polymerization and focal adhesion junction remodeling may be locally controlled by stress. In this way, the SMC can adapt its structure in order to optimally carry the forces resulting from activation and pressurization [94]. Flavahan et al. [95] demonstrate that in mouse tail arterioles, actin polymerization occurs in the myogenic response but not in phenylephrine-induced constriction. At low pressure, F-actin staining was found at the cell periphery, while at high pressure, F-actin increased in the cell interior.

Intermediate filaments in vascular SMC contain vimentin as the most prominent protein, while in smaller vessels desmin is also present $[96,97]$. Vimentin is a substrate for transglutaminases, which are possibly involved in the dimerization process [98]. These filaments extend from the nucleus to the membrane, and also connect to the dense bodies. Vimentin filaments form a dynamic network whose organization is dependent on contractile stimuli. Thus, in airway SMC, serotonin induces a shift from a random network of curved fibers to a network of straight fibers along the long axis of the SMC in 5-15 min 
$[99,100]$. Phosphorylation of Ser-56 occurs in response to contractile activation. This mediates intermediate filament disassembly [99-102], increasing the disassembled fraction of vimentin from around 10 to $20 \%[99,102]$. Vimentin depletion by antisense mutation suppresses force development while signaling remains intact, underlining the requirement of these filaments for contraction [102, 103]. Likewise, in desmin ${ }^{-1-}$ mice, small artery potential for active force development [97] and phenylephrine-induced tone [104] were impaired. As reviewed by Tang [105], the effect of the vimentin network on contractile properties may stem from several structural and regulatory aspects. The connection to the membrane at desmosomes and to cytoplasmic dense bodies, and thus to the actin fibers provides a base for force transmission. Vimentin organization may further guide the actin network and actin polymerization. Stimulus-induced depolymerization and reorganization of vimentin could thereby mediate the actin reorganization that seems so crucial for prolonged force generation. The vimentin cytoskeleton may also regulate the distribution of p130 Crk-associated substrate (CAS). The CAS family serves as docking stations for integrin-mediated signaling [106], and translocation of CAS dissociated from vimentin may facilitate actin polymerization and force development $[100,107]$. Vimentin may also translocate and activate Rho-kinase, which was shown to be involved in small artery basal tone maintenance [108]. It remains to be established how critical these processes are in the small arteries. Similarly, the mechanisms by which desmin affects force in small arteries also need to be unraveled.

Microtubuli are made of tubulin dimers that nucleate at microtubule organizing centers such as the centrioles and basal bodies. They are well known to be crucial for mitosis, for dynamic positioning of organelles within cells [109], and for cell motility. Microtubule disruption increases the force of SMC [110]. A cell signaling component is present [111-113], but increased force or shortening also occurs in maximally active SMC, providing evidence for their role in tensegrity, a model for mechanical balance of cells in which actin elements act as prestretched fibers and the microtubules as rigid struts opposing the force generated by the actin filaments [114]. On the other hand, microtubule destruction or stabilization did not affect the unloaded shortening velocity of permeabilized vascular SMC [115] and intact coronary arteries [116]. A role for microtubules in migration of vascular SMC in neo-intima formation is well recognized and forms the therapeutic base of taxol-eluting stents [117]. Considering that early eutrophic remodeling of small arteries involves increased overlap and therefore motility of SMC [118], it may well be that microtubules play a role in regulation of media architecture and vascular caliber. Clearly, this area needs more research.

\section{Mechanical Properties of the Maximally Active Small Artery Wall}

As was the case for the passive steady state mechanical properties, those of the small artery at full activation can be determined using isometric techniques. Figure $2 \mathrm{~b}$ depicts a typical relation. Active tension is determined by subtracting the passive tension from total tension, assuming a parallel arrangement. Arteries display a gradual increase in maximal active tension at larger distension, generally reaching a peak at radii smaller than $r_{100}$, followed by a decline at further distensions. Remodeling of the SMC causes a change in this relation. The grey curve and dotted arrow in figure $2 \mathrm{~b}$ indicate remodeling towards a smaller optimal diameter.

Peak tension (i.e. force/length) is higher in larger vessels. This is mainly related to a thicker wall, such that active stress is more comparable between vessels of different caliber $[119,120]$. We previously obtained isometric radius-pressure curves on cannulated small mesenteric arteries, using radius-driven feedback of the pressure [121]. We found that the capacity for 'active pressure' generation is close to $200 \mathrm{~mm} \mathrm{Hg}$ for these vessels. Translating these curves into radius-tension curves on the basis of the Laplace law reveals a similar shape as found on the wires, indicating that the non-circular shape in wiremounted preparations has little influence. A consequence of these relations is that at physiological and mildly higher pressures, fully active vessels remain almost closed.

The factors that determine the shape of the active radius-tension relation may include both the organization of the contractile and cytoskeletal elements, as discussed above, and the deformation of the vascular wall during constriction $[119,120]$. In constricted vessels, the luminal surface of the vessel folds into ridges, consisting of not only the endothelial cells and internal elastic lamina, but also part of the SMC [77]. This withdraws part of the SMC from the capacity for tangential force generation. This process of ridge formation has been suggested to depend on dense body organization and to be associated with reorientation of the myofilaments [122]. Vessel mass luminal to the contractile filaments may furthermore amplify the effect of contraction on diameter reduction, while steric hindrance between ridges may prevent full closure.

While small artery remodeling is commonly expressed in terms of a change in passive properties, the changes in 
maximal active radius-tension relations such as those indicated in figure $2 b$ have hardly been studied. Yet it is clear that this relation is tightly controlled. Thus, the optimum radius for active tension is linked to the passive radius. This link is found over many orders of vascular caliber, and apparently is maintained during growth and development. In addition, SMC length is fairly independent of vascular caliber (see above). Therefore, regulation of SMC length, in addition to the regulation of cytoskeletal organization, may underlie shifts in active radiustension relations during remodeling.

\section{Small Artery SMC and Matrix Remodeling}

Vascular remodeling reflects any change in vascular structure, including changes in lumen diameter, wall thickness and wall composition, in terms of cellular parameters and amount of ECM components. In addition, organization of these components may change, such that the functional or mechanical behavior of the vessel has changed. Remodeling is preferentially described in terms of shifts in mechanical characteristics of individual vessels. In addition, describing 'remodeling' (or altered modeling) between groups can be based on the wall-to-lumen ratio, or media-to-lumen ratio. This term allows the comparison of vessels from different individuals, irrespective of the anatomical location, size or branching order. To our knowledge, whether the wall-to-lumen ratio is constant over the arterial tree is a question that has not been extensively studied. Data in mice show that the wall-tolumen ratio is similar in aorta, carotid and mesenteric arteries [123]. However, data from Frobert et al. [124] suggest that porcine coronary arteries show an increase in wall-to-lumen ratio with an increase in branching order. Similar findings have been made by Bevan et al. [125] for human pial arteries. A concern of these studies is that different experimental conditions, such as varying pressure levels, were used. It is not obvious at which pressure, or pressures, these measurements should be made when vessels of different origin are compared. Some general recommendations regarding this issue have been made by Bund and Lee [126]. While the wall-to-lumen ratio is undoubtedly increased in hypertension, it provides little information on the underlying process, which could be an increase in wall mass (hypertrophy or hyperplasia), a decrease in lumen diameter, or a combination of both. A useful graphical representation of the types of remodeling is given by Mulvany et al. [127] where the authors define remodeling on the basis of lumen change (inward or outward) and wall cross-sectional area (hypertrophic, hypotrophic or eutrophic). The contribution of each parameter depends on the particular model, but is dominated by eutrophic remodeling, i.e. a rearrangement of material around a smaller lumen without a change in wall cross-sectional area, in the case of essential hypertension [128]. However, it should be stressed that SMC proliferation and apoptosis may form part of the remodeling of small arteries [6].

\section{Tone Drives Remodeling}

We found that chronic vasoconstriction in vitro results in the inward remodeling of small arteries [129, 130]. In addition, some arteries show outward remodeling in vitro in response to prolonged exposure to vasodilators. These observations have led to the suggestion that tone determines the direction of the remodeling response. This idea is in good agreement with results in hypertensive subjects, where vasodilator treatment, but not blood pressure reduction per se, corrects vascular structure [1]. This is of importance, since an increased wall-to-lumen ratio is a predictor of cardiovascular events [131, 132]. In models of altered blood flow, changes in tone precede actual remodeling $[133,134]$. These changes in tone appear to be an essential intermediary step in the remodeling process, since defective endothelial function and/or flowinduced dilation prevents flow-induced remodeling [135138].

Based on the wall constituents described above and their dynamic structures, tone-remodeling coupling may occur by 2 pathways, one related to the cytoskeleton and the other to the 'mold' that is provided for newly formed extracellular matrix elements. Regarding the first pathway, in a recent review [139], Martinez-Lemus et al. argue that the boundaries between constriction and remodeling are blurred. They propose that the sequence of events from vasoconstriction, to intracellular reorganization of the cytoskeleton, to cellular repositioning and, eventually, a change in the passive vessel diameter, should not be considered as separate events but rather as a continuum. These events rely on overlapping pathways and depend on the same structural elements, which form the cytoskeleton-integrin-extracellular matrix axis. This concept is based on experiments with isolated arteries that are contracted for various periods. Thus, following a 5 -minute constriction, vessels fully relax to their original diameter. When constriction is maintained for $4 \mathrm{~h}$, removal of the constrictor does not result in complete relaxation [118]. The prolonged state of constriction is associated with increased overlap of the SMC and relength- 
ening of the SMC during the maintained vasoconstriction. The lack of full dilation would thus reflect a cytoskeletal brake on distension, and in early remodeling the cytoskeleton would thus take over this function from collagen. The repositioning of SMCs is suggested to redistribute wall stress to non-contractile vessel elements, thereby minimizing SMC energy expenditure [139]. A relengthening of cells in constricted vessels would also cause a leftward shift of the active radius-tension curve, provided that the intracellular organization remains unaffected. We analyzed this relation in small arteries mounted in a wire-myograph setup, which were activated at either low or high distension with endothelin-1 [130]. Here we found that only vessels that are activated at low distension indeed showed a shift in the active length-tension relationship towards a smaller diameter. Yet, from work by Gunst, Seow and others indicated above on non-vascular SMC, it is highly likely that not only the cell length but also the organization of the contractile and cytoskeletal elements changes during such maintained vasoconstriction. Thus, during early remodeling, prior to matrix reorganization, there may be adaptation both of the SMC length [118] and to the SMC length [91]. Figure 4 provides a schematic drawing of such SMC plasticity. Following chronic vasoconstriction (fig. 4a, b), rearrangement of the actomyosin elements would shift the active radius-tension curve leftwards, while reorganization of the cytoskeleton would prevent distension towards the original diameter (fig. 4c). Relengthening of the cells and increased overlap would induce similar macroscopic effects (fig. 4d). Further work is needed to unravel the nature, balance and reversibility of these processes in early remodeling. It would, furthermore, be of interest to test whether the myogenic reactivity is shifted after prolonged constriction and relengthening of SMC.

An important consequence of the model proposed by Martinez-Lemus is that the traditional view of load-bearing structures under active and passive conditions needs to be reconsidered. Thus, under prolonged deep constriction, part of the load is transferred away from active actomyosin cross-bridge cycling, and SMC are able to reposition within the vessel wall. After subsequent relaxation, part of the load appears to be carried by cytoskeletal elements, rather than by elastin and collagen alone. The question rises whether cytoskeletal elements also limit distension of vessels that are not subjected to prolonged deep constriction. Experiments using cytochalasins indicate that this is not the case. Cytochalasins are widely used to study the cytoskeletal contribution to cell stiffness and motility. By binding to the growing ends of mi- crofilaments, they block both assembly and disassembly of actin monomers [140]. In our hands, cytochalasin D does not increase the passive diameter of freshly isolated vessels (unpubl. data). Cytochalasin B lowered the pressure for forced dilation of cerebral vessels at normal tone, but did not seem to change the passive diameter at high pressure [141]. In desmin ${ }^{-/-}$mice, passive stresses as well as maximal active stresses were clearly reduced in second order mesenteric resistance vessels. Yet this might reflect altered development rather than a role for desmin in acute passive mechanics [97]. If, indeed, in an established structure the extracellular fibers determine the maximal diameter, and considering the link between diameter for optimal active tension and passive diameter, it follows that mechanisms exist that adapt the extracellular matrix to the contractile and cytoskeletal properties of the SMC.

Such a mechanism could reside in the 'mold' that is provided by the active vessel diameter (fig. 5). If newly formed matrix components are embedded in a constricted blood vessel, it can be envisioned that this would result in a reduction of the passive diameter [142]. In the reverse case, when new matrix components such as collagen fibers are loosely placed in a vasodilated artery, the maximal diameter may ultimately increase. In this 'mold' hypothesis inward remodeling may even occur in the absence of newly formed material, when the existing matrix components are cross-linked by, for example, transglutaminases. Data from our group and others have shown that members of this family of enzymes can induce small artery remodeling both in vitro and in vivo in hypertension and flow-induced remodeling [143-146]. The role of transglutaminases in remodeling was recently reviewed [31]. The relationship between tone and remodeling may be further strengthened by the overlap in signaling pathways, which is evident from various studies. Thus, angiotensin II and endothelin-1 are known to induce proliferation and fibrosis in addition to inflammation and vasoconstriction, as reviewed by Intengan and Schiffrin [6]. The vasodilator signaling of nitric oxide also overlaps with remodeling events, but diverges at the level of cGMPdependent protein kinase type I [147].

\section{Inflammation Facilitates Remodeling}

A specific type of remodeling is the outgrowth of small pre-existing collateral arteries in the face of an arterial obstruction. This process is referred to as arteriogenesis [148] and may be considered an extreme case of flow-induced remodeling. It is particularly relevant in the case of large artery stenosis which results from atherosclerot- 
ic lesions as it provides a natural bypass to alleviate ischemia [149]. This is an area of intense research, which has mainly focused on the stimulation of leukocyte recruitment to the area of vascular remodeling [150]. These leukocytes, particularly monocytes, but also natural killer cells (a specific lymphocyte with regulatory as well as cytotoxic functions) and CD4+ T cells [151] facilitate arteriogenesis, probably through the release of metalloproteinases and cytokines. We found that both inward and outward remodeling in small mesenteric arteries of mice induced by altered blood flow depends on macrophages [152]. A similar dependence on leukocytes is found in pregnancy-induced vascular remodeling. In this case, natural killer cells play a crucial role in the dramatic outward remodeling of uterine arteries, which depends on interferon- $\gamma$ release $[153,154]$. In experimental hypertension, the inward remodeling of small arteries is dependent on proper macrophage function $[155,156]$. Our current view is that the inward or outward direction of remodeling is linked to cytoskeletal reorganization and tone as indicated above, while inflammatory mechanisms would facilitate this process through degradation, cross-linking and rebuilding the extracellular matrix. Yet it is clear that this needs further research.

\section{Pressure-Dependent Remodeling}

While many stimuli and conditions influence regulation of small artery caliber, pressure plays a special role since it determines the stresses and strains on the wall elements and is a direct stimulus for SMC contraction. Hypertension is also one of the most relevant fields for remodeling research. The myogenic response, i.e. the increase in tone and reduction in diameter with pressure, was described by Bayliss as early as 1902 [157]. Johnson pointed out that the myogenic response regulates total wall tension [3]. This concept is still in use [158, 159]. VanBavel et al. [63] and Buus et al. [58] pointed out that total wall tension is influenced by vasoactive agents. Therefore, the myogenic response would not only regulate wall tension against changes in pressure, but also oppose vasoconstrictive influences under pressure-driven conditions (since the vasoconstriction causes a reduction of wall tension) while amplifying them under isometric conditions (since here the activation raises total wall tension). Signaling in the myogenic response has been well reviewed [160-164]. The response invokes calcium signaling, but also heavily depends on the cytoskeleton and integrin signaling. Pressure-dependent remodeling may relate to such signaling. In addition, the strength of the myogenic response may influence the nature of the re- modeling. Thus, wall stress in hypertension can be normalized by inward eutrophic remodeling or hypertrophy. On the basis of the 'mold' hypothesis, the eutrophic inward remodeling in small arteries may be the consequence of the strong myogenic response known to exist in these vessels, while large vessels show both a limited myogenic response (i.e. increased diameter at increased pressure) and hypertrophic responses to hypertension. In support of this view, in hypertensive models with compromised myogenic responses, small vessels show hypertrophic remodeling [165].

\section{Quantitative Approaches to Vascular Remodeling}

Functional and structural responses of small arteries to mechanical and metabolic stimuli are considered to serve homeostasis of tissue perfusion, wall stress and shear stress. Figure 6 indicates tone, plasticity and remodeling as a sequence of events in a possible control loop. Interaction schemes such as this can be refined and extended to networks and metabolic variables. Yet the presence of multiple regulated variables, acute and structural effects, and the complexity of network architecture [166-168] obscures a straightforward insight into the integrated behavior of the resistance vasculature. Several authors built simulation models of vascular regulation in order to obtain a better understanding or to derive new concepts for vascular regulation. To the best of our knowledge, no network-based models have been published that combine tone, remodeling, wall stress, shear stress and metabolic influences in an integrated approach. It is indeed questionable whether such an approach would be insightful at this moment. A more sensible strategy is to take this step by step. Here we suggest a definition of tone that can be used for modeling purposes and we highlight a number of model studies and concepts on diameter regulation of single segments that seem relevant for the progress towards an integrated approach in this area.

\section{How to Quantify Tone?}

'Vascular tone' is often defined as the degree of vasoconstriction, expressed as a percentage reduction in diameter. While this definition is fully justified for descriptive and statistical purposes and for interpretations in terms of vascular resistance, a more fundamental definition may be based on the state of contractile activation of the SMC. Thus, assuming a single SMC compartment parallel to the matrix, tone can also be defined as the actual active tension divided by the maximal active tension 
4

Fig. 4. Schematic representation of possible SMC plasticity and the consequences on vascular caliber. a Left: a relaxed, pressurized vessel, consisting of spindleshaped SMC (yellow) surrounded by distended matrix elements (black). Right: a single SMC, with dense bodies (black), a cytoskeleton (purple) and contractile elements (black actin, green myosin). b The same vessel in a deeply contracted state. Actomyosin interaction carries the tension, while matrix and subcortical cytoskeleton become unloaded. Capacity for tension generation becomes less due to reduced amount of effective myosin (green dashed lines). c, d Alternative hypotheses for SMC plasticity during prolonged activation. In c, the reduction of number of actomyosin elements in series would induce a leftward shift of the active radius-tension curve. Reorganization of the cytoskeleton would prevent dilation to the original diameter upon SMC relaxation. In $\mathbf{d}$, possible relengthening and rearrangement of SMC during prolonged activation is shown. Overlap of SMC in the wall increases, the active radius-tension curve would shift leftward, and the cytoskeleton would prevent dilation to the original diameter.

Fig. 5. The 'mold' hypothesis linking vasoconstriction to inward remodeling. a Part of the relaxed vessel wall, showing a SMC (yellow), matrix fibers (black) and crosslinks (blue). b Contraction unloads the existing matrix. c Matrix turnover. A new matrix element (brown) is embedded that is relatively straight in the constricted vessel. In addition, new cross-links (orange) are formed between and within new and existing matrix. Some old elements have disappeared. d Upon SMC relaxation, the new elements and cross-links prevent dilation to the original diameter.

Fig. 6. Vascular tone as a central element in a sequence of interactions regulating local tissue perfusion and peripheral resistance.

6

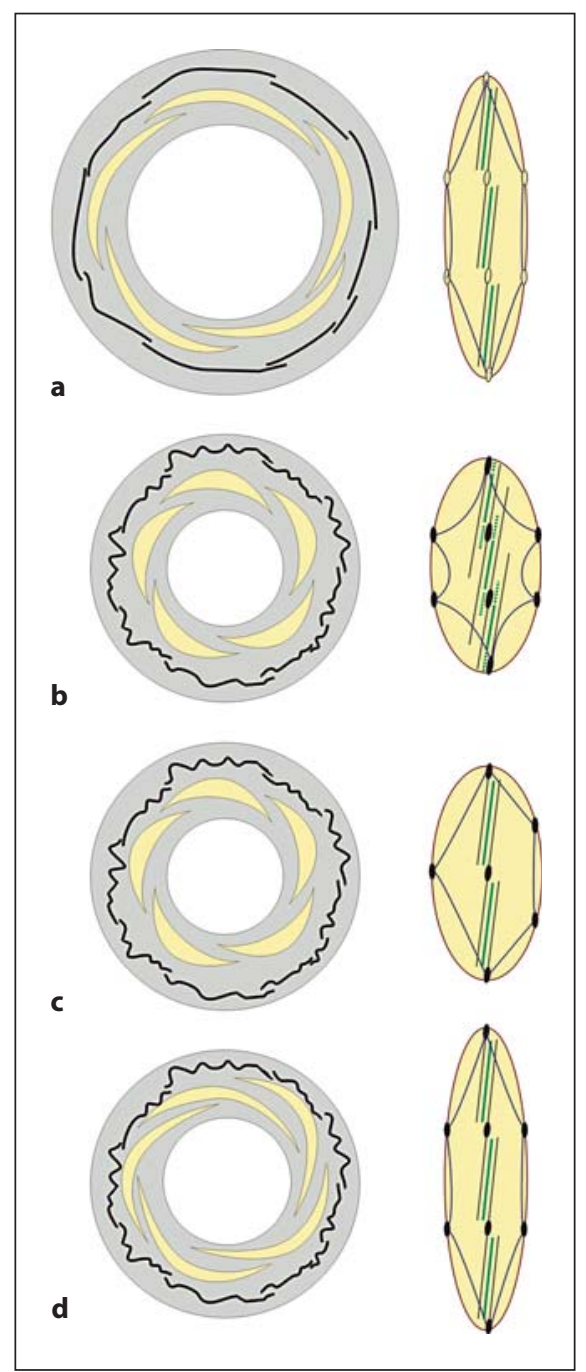

5
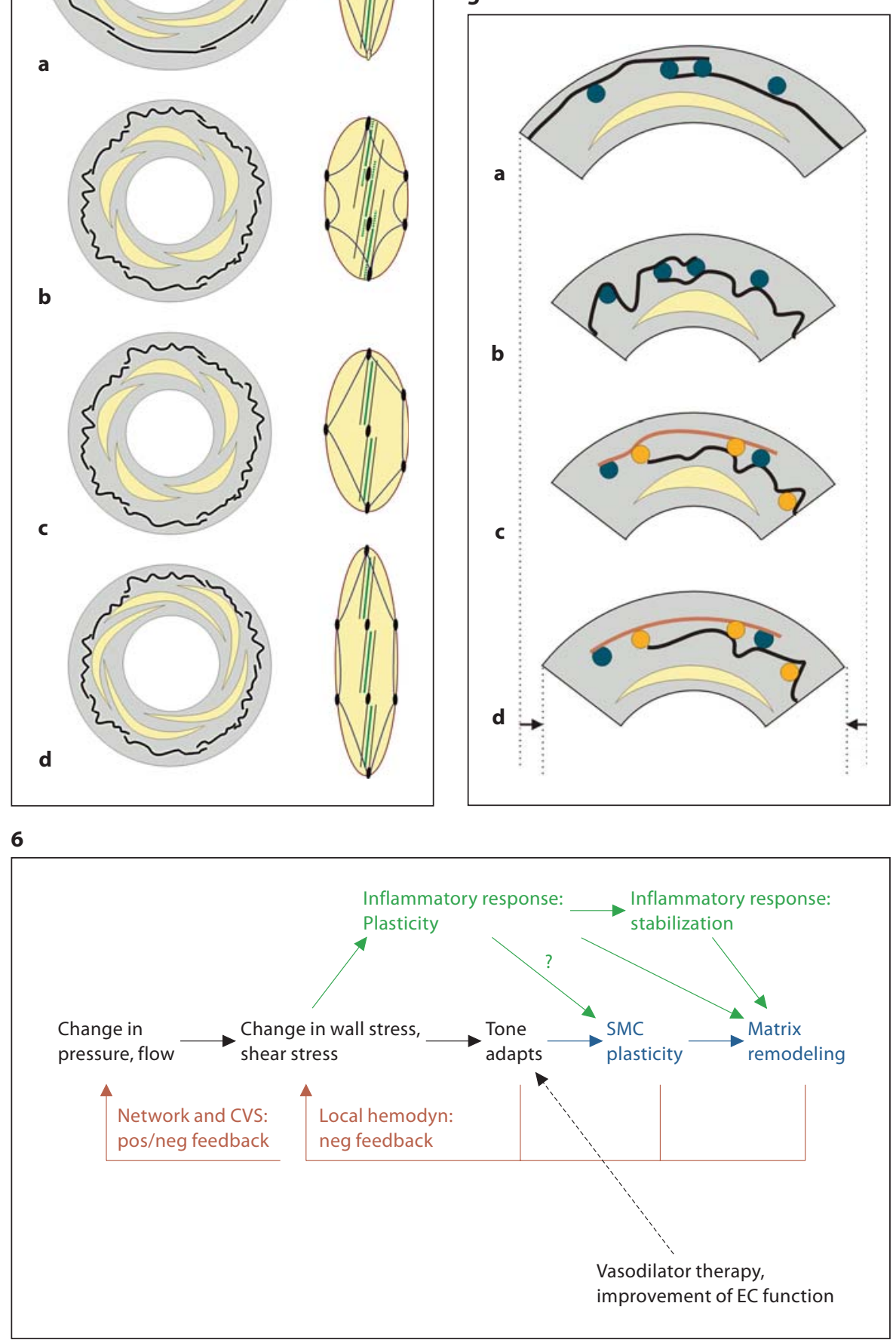
at the same diameter. Several experimental $[63,108,121]$ and model studies $[158,159,169,170]$ have employed this definition. Figure $2 \mathrm{c}$ and $\mathrm{d}$ depict radius-tension and pressure-radius curves at various levels of tone according to this definition. As can be seen in fig. $2 \mathrm{~d}$, radius at any constant tone level increases rapidly with pressure. Vessels therefore need to increase tone with pressure (myogenic response) even to maintain a constant diameter, let alone to obtain a negative myogenic pressure-diameter slope (dash-dot line in fig. 2d).

\section{Tone as a Drive for Remodeling}

The concept that tone drives remodeling was quantitatively analyzed by Jacobsen and co-workers [159]. These authors built a simulation model based on a wall stressdriven myogenic response in combination with tone-dependent inward or outward eutrophic remodeling. While the authors made specific choices for passive and active radius-stress curves and dynamics of adaptation, the model is in essence a conceptual one, and the conclusions seem valid for a wide array of parameter choices. An increase in pressure resulted in activation and vasoconstriction, as discussed above, but at a longer time scale also induced inward remodeling. This again helps to restore wall stress and causes gradual reduction of tone during the remodeling response. In steady state, at higher pressure the vessel became inwardly remodeled with unchanged basal tone. This model was further tested by simulating vasodilator and vasoconstrictor influences, from for example surrounding tissue and nerve endings. Continuous presence of a vasodilator caused outward remodeling, but tone was restored to original levels. Thus, by having an adaptive response of tissue structure driven by tone, vessels in this model are able to maintain a normal level of activation under a wide variety of chronic conditions. Tone, according to this model, could therefore be regarded as a long-term regulated variable. The exact myogenic responsiveness and the existence or not of a negative slope in the active pressure-diameter relation is not critical in this model. Thus, variations in the myogenic responsiveness, known to exist in the circulation [158], lead to differences in chronic tone but, possibly counter-intuitively, not to differences in passive vessel caliber.

The model of Jacobsen provides quite a useful approach in understanding integrated regulation of caliber. At the same time, it generates additional questions. The first question is what is actually being regulated in vessels in a network? The Jacobsen model considers regulation of wall stress as the drive for remodeling via tone. Other influences were considered to be simple, uncontrolled offsets in tone, eventually causing structural effects. This all occurs under the condition of controlled pressure, and indeed the authors pointed out that their model simulates an isolated, cannulated vessel under pressure control. However, one might also subject such a vessel to flow control. On the basis of both acute and chronic effects of flow, it has been argued that flow-dependent tone and remodeling act to regulate shear stress [158]. One could construct a tone-remodeling model where tone depends on shear stress. A step increase in flow here would lead to increased shear stress, vasodilation, outward remodeling, reduction in shear stress and recovery of tone to its original level. Other vasoactive factors would lead to changed caliber with unaltered tone in steady state. Sensitivity to shear would influence the chronic level of tone, but not the caliber of the vessel. Such a model would thus be completely analogues to the Jacobsen model, but with pressure exchanged for flow. In a network, alterations in vascular tone and remodeling affect both pressure and flow, while metabolic influences, such as the local oxygen concentration, might also be considered to form regulated quantities. Therefore, a necessary further step is to build models combining acute regulation of both wall stress and shear stress with tone-remodeling coupling. These models should initially be analyzed in a setting with constant entrance and exit resistances. Once properly understood, such models could be incorporated in simulations of vascular networks.

\section{Modeling Matrix Rearrangement and Turnover}

Jacobsen et al. incorporated tone-driven remodeling as a change over time of the unloaded passive diameter, without specification of turnover or rearrangement of individual fibers that underlines such change. A next step could be to include turnover of populations of fibers with dispersion of resting lengths. As an example, Gleason and Humphrey $[171,172]$ formulated conceptual models of large artery growth and remodeling in hypertension based on turnover of vascular elements. The model was based on the assumption that the individual wall elements deform together, but can turnover at different rates, based on the stresses acting on these elements. New elements would have resting lengths matched to the actual diameter of the vessel. Tone was included, but only as a way to maintain the actual diameter against changes in pressure. The authors concluded that stress-dependent turnover ensures normalization of wall stress, through increased wall mass. Differences in turnover rate between elastin, collagen and SMC would cause a stiffening 
of the vessel during hypertension. Such predictions reflect the hypertrophic rather than eutrophic remodeling of large vessels in hypertension. It needs to be established to what extent known differences in tone control between large and small arteries would affect predictions for remodeling based on such a turnover approach. As indicated above, a further concern in such turnover approaches is that the predictions rely heavily on the arrangement of collagen as parallel or serial elements [72]. Clearly, more experimental evidence is needed for the rates of turnover and arrangement of existing and new fibers.

\section{Conclusions}

It is clear that the questions provided in the introduction with respect to integrated regulation of small artery caliber and flow cannot yet be answered. The bottle necks include the need for a better understanding of small artery matrix architecture, maintenance and mechanics, more extensive experimental data on SMC mechanics in remodeling vessels, and a better insight into regulation of SMC cell length and cytoskeletal architecture. We believe that there is much to learn from current progress in nonvascular SMC biophysical research. Considering the size and transparency of small arteries, the rapid progress in molecular and live imaging techniques should provide many new experimental approaches, allowing the bridging of cellular and matrix biophysics and vascular biomechanics. More detailed molecular information will remain needed, but simultaneously we should make sure we 'see the physiological wood through the molecular trees', and this requires a combined experimental and modeling approach.

\section{Acknowledgments}

Jeroen van den Akker is supported by the Netherlands Heart Foundation project NHS.2005.B080. Marieke Schoorl is supported by the Top Institute Pharmacology project T2-108.

\section{References}

1 Christensen KL, Mulvany MJ: Vasodilatation, not hypotension, improves resistance vessel design during treatment of essential hypertension: a literature survey. J Hypertens 2001;19:1001-1006.

2 Verhoeff BJ, Siebes M, Meuwissen M, Atasever B, Voskuil M, de Winter RJ, Koch KT, Tijssen JG, Spaan JA, Piek JJ: Influence of percutaneous coronary intervention on coronary microvascular resistance index. Circulation 2005; $111: 76-82$

3 Johnson PC: The myogenic response; in Bohr DR, Somlyo AP, Sparks HV Jr (eds): Handbook of Physiology. Bethesda, American Physiological Society, 1980, vol 2, pp 409-442.

4 Rubio R, Berne RM: Release of adenosine by the normal myocardium in dogs and its relationship to the regulation of coronary resistance. Circ Res 1969;25:407-415.

$\checkmark 5$ Merkus D, Duncker DJ, Chilian WM: Metabolic regulation of coronary vascular tone: role of endothelin-1. Am J Physiol Heart Circ Physiol 2002;283:H1915-H1921.

-6 Intengan HD, Schiffrin EL: Vascular remodeling in hypertension: roles of apoptosis, inflammation, and fibrosis. Hypertension 2001;38:581-587.

7 Halpern W, Kelley M: In vitro methodology for resistance arteries. Blood Vessels 1991;28: 245-251.
8 Mulvany MJ, Halpern W: Mechanical properties of vascular smooth muscle cells in situ. Nature 1976;260:617-619.

-9 Bevan JA, Osher JV: A direct method for recording tension changes in the wall of small blood vessels in vitro. Agents Actions 1972; 2:257-260.

10 Mulvany MJ, Halpern W: Contractile properties of small arterial resistance vessels in spontaneously hypertensive and normotensive rats. Circ Res 1977;41:19-26.

11 Mulvany MJ, Warshaw DM: The active tension-length curve of vascular smooth muscle related to its cellular components. J Gen Physiol 1979;74:85-104.

12 Burg M, Grantham J, Abramow M, Orloff J: Preparation and study of fragments of single rabbit nephrons. Am J Physiol 1966;210: 1293-1298.

$>13$ Duling BR, Gore RW, Dacey RG Jr., Damon DN: Methods for isolation, cannulation, and in vitro study of single microvessels. Am J Physiol 1981;241:H108-H116.

14 Vanbavel E, Mooij T, Giezeman MJ, Spaan JA: Cannulation and continuous cross-sectional area measurement of small blood vessels. J Pharmacol Methods 1990;24:219-227.

15 Kuo L, Davis MJ, Chilian WM: Myogenic activity in isolated subepicardial and subendocardial coronary arterioles. Am J Physiol 1988;255:H1558-H1562.
16 Spencer JA, Hacker SL, Davis EC, Mecham RP, Knutsen RH, Li DY, Gerard RD, Richardson JA, Olson EN, Yanagisawa H: Altered vascular remodeling in fibulin-5-deficient mice reveals a role of fibulin-5 in smooth muscle cell proliferation and migration. Proc Natl Acad Sci USA 2005;102:2946-2951.

17 Rhodin JAG: Architecture of the vessel wall; in Bohr DR, Somlyo AP, Sparks HV Jr (eds): Handbook of Physiology. Bethesda, The American Physiological Society, 1980, vol 2, $1-29$.

18 Mulvany MJ, Aalkjaer C: Structure and function of small arteries. Physiol Rev 1990; 70:921-961.

19 Gonzalez JM, Briones AM, Starcher B, Conde MV, Somoza B, Daly C, Vila E, McGrath I, Gonzalez MC, Arribas SM: Influence of elastin on rat small artery mechanical properties. Exp Physiol 2005;90:463-468.

20 Sorop O, Bakker EN, Pistea A, Spaan JA, Vanbavel E: Calcium channel blockade prevents pressure-dependent inward remodeling in isolated subendocardial resistance vessels. Am J Physiol Heart Circ Physiol 2006;291:H1236-H1245.

21 Wagenseil JE, Mecham RP: New insights into elastic fiber assembly. Birth Defects Res C Embryo Today 2007;81:229-240. 
-22 Jacob MP, Badier-Commander C, Fontaine V, Benazzoug Y, Feldman L, Michel JB: Extracellular matrix remodeling in the vascular wall. Pathol Biol (Paris) 2001;49:326-332.

-23 Partridge SM, Elsden DF, Thomas J, Dorfman A, Telser A, Ho PL: Incorporation of labelled lysine into the desmosine cross-bridges in elastin. Nature 1966;209:399-400.

24 Partridge SM, Elsden DF, Thomas J: Constitution of the cross-linkages in elastin. $\mathrm{Na}$ ture 1963;197:1297-1298.

-25 Ushiki T: Collagen fibers, reticular fibers and elastic fibers: a comprehensive understanding from a morphological viewpoint. Arch Histol Cytol 2002;65:109-126.

-26 Mithieux SM, Weiss AS: Elastin. Adv Protein Chem 2005;70:437-461.

-27 Kielty CM, Sherratt MJ, Shuttleworth CA: Elastic fibres. J Cell Sci 2002;115:2817-2828.

-28 Qian RQ, Glanville RW: Alignment of fibrillin molecules in elastic microfibrils is defined by transglutaminase-derived crosslinks. Biochemistry 1997;36:15841-15847.

-29 Mecham RP, Broekelmann T, Davis EC, Gibson MA, Brown-Augsburger P: Elastic fibre assembly: macromolecular interactions. Ciba Found Symp 1995;192:172-181.

>30 Arribas SM, Hinek A, Gonzalez MC: Elastic fibres and vascular structure in hypertension. Pharmacol Ther 2006;111:771-791.

-31 Bakker EN, Pistea A, Vanbavel E: Transglutaminases in vascular biology: relevance for vascular remodeling and atherosclerosis. J Vasc Res 2008;45:271-278.

32 Fung YC: Biomechanics: Mechanical Properties of Living Tissues. New York, SpringerVerlag, 1980.

-33 Urry DW, Parker TM: Mechanics of elastin: molecular mechanism of biological elasticity and its relationship to contraction. J Muscle Res Cell Motil 2002;23:543-559.

34 Debelle L, Alix AJ: The structures of elastins and their function. Biochimie 1999;81:981994.

-35 Li B, Daggett V: Molecular basis for the extensibility of elastin. J Muscle Res Cell Motil 2002;23:561-573.

36 Hoeve CA, Flory PJ: The elastic properties of elastin. Biopolymers 1974;13:677-686.

>37 Hsu-Wong S, Katchman SD, Ledo I, Wu M, Khillan J, Bashir MM, Rosenbloom J, Uitto J: Tissue-specific and developmentally regulated expression of human elastin promoter activity in transgenic mice. J Biol Chem 1994;269:18072-18075

- 38 Indik Z, Yeh H, Ornstein-Goldstein N, Sheppard P, Anderson N, Rosenbloom JC, Peltonen L, Rosenbloom J: Alternative splicing of human elastin mRNA indicated by sequence analysis of cloned genomic and complementary DNA. Proc Natl Acad Sci USA 1987;84:5680-5684.

-39 Walker-Caprioglio HM, Trotter JA, Mercure J, Little SA, McGuffee LJ: Organization of rat mesenteric artery after removal of cells of extracellular matrix components. Cell Tissue Res 1991;264:63-77.
40 Ottani V, Martini D, Franchi M, Ruggeri A, Raspanti M: Hierarchical structures in fibrillar collagens. Micron 2002;33:587-596.

41 Petruska JA, Hodge AJ: A Subunit model for the tropocollagen macromolecule. Proc Natl Acad Sci USA 1964;51:871-876.

42 Orgel JP, Irving TC, Miller A, Wess TJ: Microfibrillar structure of type I collagen in situ. Proc Natl Acad Sci USA 2006;103:9001-9005.

43 Liao J, Vesely I: Skewness angle of interfibrillar proteoglycan increases with applied load on chordae tendineae. Conf Proc IEEE Eng Med Biol Soc 2004;5:3741-3744.

44 Rodriguez-Feo JA, Sluijter JP, de Kleijn DP, Pasterkamp G: Modulation of collagen turnover in cardiovascular disease. Curr Pharm Des 2005;11:2501-2514.

45 Janssens S, Lijnen HR: What has been learned about the cardiovascular effects of matrix metalloproteinases from mouse models? Cardiovasc Res 2006;69:585-594.

46 Behrendt N: The urokinase receptor (uPAR) and the uPAR-associated protein (UPARAP/ Endo180): membrane proteins engaged in matrix turnover during tissue remodeling Biol Chem 2004;385:103-136.

47 Lijnen HR: Plasmin and matrix metalloproteinases in vascular remodeling. Thromb Haemost 2001;86:324-333.

48 Sasaki N, Odajima S: Stress-strain curve and Young's modulus of a collagen molecule as determined by the X-ray diffraction technique. J Biomech 1996;29:655-658.

49 Misof K, Rapp G, Fratzl P: A new molecular model for collagen elasticity based on synchrotron X-ray scattering evidence. Biophys J 1997;72:1376-1381.

50 Puxkandl R, Zizak I, Paris O, Keckes J, Tesch W, Bernstorff S, Purslow P, Fratzl P: Viscoelastic properties of collagen: synchrotron radiation investigations and structural model. Philos Trans R Soc Lond B Biol Sci 2002; 357:191-197.

51 Cowan PM, McGavin S, North AC: The polypeptide chain configuration of collagen. Nature 1955;176:1062-1064.

\$2 Fratzl P, Misof K, Zizak I, Rapp G, Amenitsch $\mathrm{H}$, Bernstorff S: Fibrillar structure and mechanical properties of collagen. J Struct Biol 1998;122:119-122.

53 Sasaki N, Odajima S: Elongation mechanism of collagen fibrils and force-strain relations of tendon at each level of structural hierarchy. J Biomech 1996;29:1131-1136.

54 Liao J, Yang L, Grashow J, Sacks MS: Molecular orientation of collagen in intact planar connective tissues under biaxial stretch. Acta Biomater 2005; 1:45-54.

55 Liao J, Joyce EM, Sacks MS: Effects of decellularization on the mechanical and structural properties of the porcine aortic valve leaflet. Biomaterials 2008;29:1065-1074.
56 Schmid F, Sommer G, Rappolt M, SchulzeBauer CA, Regitnig P, Holzapfel GA, Laggner $\mathrm{P}$, Amenitsch $\mathrm{H}$ : In situ tensile testing of human aortas by time-resolved small-angle X-ray scattering. J Synchrotron Radiat 2005; 12:727-733.

57 Atakhorrami M, Sulkowska JI, Addas KM, Koenderink GH, Tang JX, Levine AJ, Mackintosh FC, Schmidt CF: Correlated fluctuations of microparticles in viscoelastic solutions: quantitative measurement of material properties by microrheology in the presence of optical traps. Phys Rev E Stat Nonlin Soft Matter Phys 2006;73:061501.

58 Buus NH, Vanbavel E, Mulvany MJ: Differences in sensitivity of rat mesenteric small arteries to agonists when studied as ring preparations or as cannulated preparations. Br J Pharmacol 1994;112:579-587.

59 Dunn WR, Wellman GC, Bevan JA: Enhanced resistance artery sensitivity to agonists under isobaric compared with isometric conditions. Am J Physiol 1994;266: H147-H155.

-60 Vanbavel E, Giezeman MJ, Mooij T, Spaan JA: Influence of pressure alterations on tone and vasomotion of isolated mesenteric small arteries of the rat. J Physiol 1991;436:371383.

-61 Koenigsberger M, Sauser R, Seppey D, Beny JL, Meister JJ: Calcium dynamics and vasomotion in arteries subject to isometric, isobaric, and isotonic conditions. Biophys J 2008;95:2728-2738.

62 McPherson GA: Assessing vascular reactivity of arteries in the small vessel myograph. Clin Exp Pharmacol Physiol 1992;19:815825.

63 Vanbavel E, Mulvany MJ: Role of wall tension in the vasoconstrictor response of cannulated rat mesenteric small arteries. J Physiol 1994;477:103-115.

64 Armentano RL, Levenson J, Barra JG, Fischer EI, Breitbart GJ, Pichel RH, Simon A: Assessment of elastin and collagen contribution to aortic elasticity in conscious dogs. Am J Physiol 1991;260:H1870-H1877.

65 Jackson PA, Duling BR: Myogenic response and wall mechanics of arterioles. Am J Physiol 1989;257:H1147-H1155.

66 Wuyts FL, Vanhuyse VJ, Langewouters GJ, Decraemer WF, Raman ER, Buyle S: Elastic properties of human aortas in relation to age and atherosclerosis: a structural model. Phys Med Biol 1995;40:1577-1597.

67 Cox RH: Passive mechanics and connective tissue composition of canine arteries. Am J Physiol 1978;234:H533-H541.

68 Dobrin PB: Mechanical properties of arteries. Physiol Rev 1978;58:397-460.

69 Briones AM, Gonzalez JM, Somoza B, Giraldo J, Daly CJ, Vila E, Gonzalez MC, McGrath JC, Arribas SM: Role of elastin in spontaneously hypertensive rat small mesenteric artery remodelling. J Physiol 2003;552:185-195. 
70 Barra JG, Armentano RL, Levenson J, Fischer EI, Pichel RH, Simon A: Assessment of smooth muscle contribution to descending thoracic aortic elastic mechanics in conscious dogs. Circ Res 1993;73:1040-1050.

71 Bank AJ, Wang H, Holte JE, Mullen K, Shammas R, Kubo SH: Contribution of collagen, elastin, and smooth muscle to in vivo human brachial artery wall stress and elastic modulus. Circulation 1996;94:3263-3270.

72 Vanbavel E, Siersma P, Spaan JA: Elasticity of passive blood vessels: a new concept. Am J Physiol Heart Circ Physiol 2003;285:H1986H2000.

73 Rachev A, Greenwald SE: Residual strains in conduit arteries. J Biomech 2003;36:661670 .

-74 Greenwald SE, Moore JE Jr, Rachev A, Kane TP, Meister JJ: Experimental investigation of the distribution of residual strains in the artery wall. J Biomech Eng 1997;119:438-444.

75 Rachev A, Hayashi K: Theoretical study of the effects of vascular smooth muscle contraction on strain and stress distributions in arteries. Ann Biomed Eng 1999;27:459-468.

76 Walmsley JG, Gore RW, Dacey RG Jr, Damon DN, Duling BR: Quantitative morphology of arterioles from the hamster cheek pouch related to mechanical analysis. Microvasc Res $1982 ; 24: 249-271$

77 Greensmith JE, Duling BR: Morphology of the constricted arteriolar wall: physiological implications. Am J Physiol 1984;247:H687H698.

78 Krizmanich WJ, Lee RM: Correlation of vascular smooth muscle cell morphology observed by scanning electron microscopy with transmission electron microscopy. Exp Mol Pathol 1997;64:157-172.

79 McGrath JC, Deighan C, Briones AM, Shafaroudi MM, McBride M, Adler J, Arribas SM, Vila E, Daly CJ: New aspects of vascular remodelling: the involvement of all vascular cell types. Exp Physiol 2005;90:469-475.

-80 Haas TL, Duling BR: Morphology favors an endothelial cell pathway for longitudinal conduction within arterioles. Microvasc Res 1997;53:113-120.

-81 Miller BG, Connors BA, Bohlen HG, Evan AP: Cell and wall morphology of intestinal arterioles from 4- to 6- and 17- to 19-weekold Wistar-Kyoto and spontaneously hypertensive rats. Hypertension 1987;9:59-68.

-82 Ushiwata I, Ushiki T: Cytoarchitecture of the smooth muscles and pericytes of rat cerebral blood vessels: A scanning electron microscopic study. J Neurosurg 1990;73:82-90.

$\checkmark 83$ Evan AP, Connors BA: Morphometric analysis of vascular smooth muscle cells by scanning electron microscopy. Int Rev Exp Pathol 1996;36:31-52.

-84 Herrera AM, McParland BE, Bienkowska A, Tait R, Pare PD, Seow CY: 'Sarcomeres' of smooth muscle: functional characteristics and ultrastructural evidence. J Cell Sci 2005; 118:2381-2392.
85 Kim HR, Appel S, Vetterkind S, Gangopadhyay SS, Morgan KG: Smooth muscle signalling pathways in health and disease. J Cell Mol Med 2008;12:2165-2180.

86 Hirano K: Current topics in the regulatory mechanism underlying the $\mathrm{Ca}^{2+}$ sensitization of the contractile apparatus in vascular smooth muscle. J Pharmacol Sci 2007;104 109-115.

87 Somlyo AP, Somlyo AV: $\mathrm{Ca}^{2+}$ sensitivity of smooth muscle and nonmuscle myosin II: modulated by $\mathrm{G}$ proteins, kinases, and myosin phosphatase. Physiol Rev 2003;83:13251358.

88 Thorneloe KS, Nelson MT: Ion channels in smooth muscle: regulators of intracellular calcium and contractility. Can J Physiol Pharmacol 2005;83:215-242.

89 Murphy RA, Rembold CM: The latch-bridge hypothesis of smooth muscle contraction. Can J Physiol Pharmacol 2005;83:857-864

90 Wang I, Politi AZ, Tania N, Bai Y, Sanderson MJ, Sneyd J: A mathematical model of airway and pulmonary arteriole smooth muscle. Biophys J 2008;94:2053-2064.

91 Bosse Y, Sobieszek A, Pare PD, Seow CY Length adaptation of airway smooth muscle. Proc Am Thorac Soc 2008;5:62-67.

92 Gunst SJ, Tang DD, Opazo SA: Cytoskeletal remodeling of the airway smooth muscle cell: a mechanism for adaptation to mechanical forces in the lung. Respir Physiol Neurobiol 2003;137:151-168.

-93 Chen X, Pavlish K, Benoit JN: Myosin phosphorylation triggers actin polymerization in vascular smooth muscle. Am J Physiol Heart Circ Physiol 2008;295:H2172-H2177.

-94 Gunst SJ, Zhang W: Actin cytoskeletal dynamics in smooth muscle: a new paradigm for the regulation of smooth muscle contraction. Am J Physiol Cell Physiol 2008;295: C576-C587.

-95 Flavahan NA, Bailey SR, Flavahan WA, Mitra S, Flavahan S: Imaging remodeling of the actin cytoskeleton in vascular smooth muscle cells after mechanosensitive arteriolar constriction. Am J Physiol Heart Circ Physiol 2005;288:H660-H669.

96 Johansson B, Eriksson A, Virtanen I, Thornell LE: Intermediate filament proteins in adult human arteries. Anat Rec 1997;247: 439-448.

97 Wede OK, Lofgren M, Li Z, Paulin D, Arner A: Mechanical function of intermediate filaments in arteries of different size examined using desmin deficient mice. J Physiol 2002; 540:941-949.

$>98$ Gupta M, Greenberg CS, Eckman DM, Sane DC: Arterial vimentin is a transglutaminase substrate: a link between vasomotor activity and remodeling? J Vasc Res 2007;44:339344.
99 Tang DD, Bai Y, Gunst SJ: Silencing of p21activated kinase attenuates vimentin phosphorylation on Ser-56 and reorientation of the vimentin network during stimulation of smooth muscle cells by 5-hydroxytryptamine. Biochem J 2005;388:773-783.

100 Li QF, Spinelli AM, Wang R, Anfinogenova Y, Singer HA, Tang DD: Critical role of vimentin phosphorylation at Ser-56 by p21activated kinase in vimentin cytoskeleton signaling. J Biol Chem 2006;281:3471634724.

101 Goto H, Tanabe K, Manser E, Lim L, Yasui Y, Inagaki M: Phosphorylation and reorganization of vimentin by p21-activated kinase (PAK). Genes Cells 2002;7:91-97.

102 Wang R, Li QF, Anfinogenova Y, Tang DD: Dissociation of Crk-associated substrate from the vimentin network is regulated by p21-activated kinase on ACh activation of airway smooth muscle. Am J Physiol Lung Cell Mol Physiol 2007;292:L240-L248.

103 Wang R, Li Q, Tang DD: Role of vimentin in smooth muscle force development. Am J Physiol Cell Physiol 2006;291:C483-C489.

104 Loufrani L, Matrougui K, Li Z, Levy BI, Lacolley P, Paulin D, Henrion D: Selective microvascular dysfunction in mice lacking the gene encoding for desmin. FASEB J 2002;16:117-119.

105 Tang DD: Intermediate filaments in smooth muscle. Am J Physiol Cell Physiol 2008;294: C869-C878.

106 Defilippi P, DiStefano P, CabodiS: p130Cas: a versatile scaffold in signaling networks. Trends Cell Biol 2006;16:257-263.

107 Tang DD, Zhang W, Gunst SJ: The adapter protein CrkII regulates neuronal WiskottAldrich syndrome protein, actin polymerization, and tension development during contractile stimulation of smooth muscle. J Biol Chem 2005;280:23380-23389.

108 Vanbavel E, van der Meulen ET, Spaan JA: Role of Rho-associated protein kinase in tone and calcium sensitivity of cannulated rat mesenteric small arteries. Exp Physiol 2001;86:585-592.

109 Tolic-Norrelykke IM: Push-me-pull-you: how microtubules organize the cell interior. Eur Biophys J 2008;37:1271-1278.

110 Nagayama K, Matsumoto T: Contribution of actin filaments and microtubules to quasi in situ tensile properties and internal force balance of cultured smooth muscle cells on a substrate. Am J Physiol Cell Physiol 2008;295:C1569-C1578.

-111 Danowski BA: Fibroblast contractility and actin organization are stimulated by microtubule inhibitors. J Cell Sci 1989;93:255266.

112 Kolodney MS, Elson EL: Contraction due to microtubule disruption is associated with increased phosphorylation of myosin regulatory light chain. Proc Natl Acad Sci USA 1995;92:10252-10256. 
113 Opitz F, Schenke-Layland K, Cohnert TU, Stock UA: Phenotypical plasticity of vascular smooth muscle cells-effect of in vitro and in vivo shear stress for tissue engineering of blood vessels. Tissue Eng 2007;13: 2505-2514.

114 Ingber DE: Tensegrity I: Cell structure and hierarchical systems biology. J Cell Sci 2003;116:1157-1173.

115 Paul RJ, Bowman PS, Kolodney MS: Effects of microtubule disruption on force, velocity, stiffness and $[\mathrm{Ca}(2+)](\mathrm{i})$ in porcine coronary arteries. Am J Physiol Heart Circ Physiol 2000;279:H2493-H2501.

-116 Zhang D, Sherwood J, Li L, Swartz DR: Unloaded shortening velocity in single permeabilized vascular smooth muscle cells is independent of microtubule status. J Muscle Res Cell Motil 2004;25:167-175.

117 Gruchalla KJ, Nawarskas JJ: The paclitaxeleluting stent in percutaneous coronary intervention. Part I. Background and clinical comparison to bare metal stents. Cardiol Rev 2006;14:88-98.

-118 Martinez-Lemus LA, Hill MA, Bolz SS, Pohl U, Meininger GA: Acute mechanoadaptation of vascular smooth muscle cells in response to continuous arteriolar vasoconstriction: implications for functional remodeling. FASEB J 2004;18:708-710.

119 Davis MJ, Gore RW: Length-tension relationship of vascular smooth muscle in single arterioles. Am J Physiol 1989;256:H630 H640.

120 Gore RW, Davis MJ: Mechanics of smooth muscle in isolated single microvessels. Ann Biomed Eng 1984;12:511-520.

121 Vanbavel E, Wesselman JP, Spaan JA: Myogenic activation and calcium sensitivity of cannulated rat mesenteric small arteries. Circ Res 1998;82:210-220.

-122 Sleek GE, Duling BR: Coordination of mural elements and myofilaments during arteriolar constriction. Circ Res 1986;59:620-627.

123 Dilley RJ, Schwartz SM: Vascular remodeling in the growth hormone transgenic mouse. Circ Res 1989;65:1233-1240.

-124 Frobert O, Gregersen H, Bjerre J, Bagger JP, Kassab GS: Relation between zero-stress state and branching order of porcine left coronary arterial tree. Am J Physiol 1998; 275:H2283-H2290.

125 Bevan JA, Dodge J, Walters CL, Wellman T, Bevan RD: As human pial arteries (internal diameter 200-1000 microm) get smaller, their wall thickness and capacity to develop tension relative to their diameter increase. Life Sci 1999;65:1153-1161.

-126 Bund SJ, Lee RM: Arterial structural changes in hypertension: a consideration of methodology, terminology and functional consequence. J Vasc Res 2003;40:547-557.

127 Mulvany MJ, Baumbach GL, Aalkjaer C, Heagerty AM, Korsgaard N, Schiffrin EL, Heistad DD: Vascular remodeling. Hypertension 1996;28:505-506.
128 Heagerty AM, Aalkjaer C, Bund SJ, Korsgaard N, Mulvany MJ: Small artery structure in hypertension: dual processes of remodeling and growth. Hypertension 1993; 21:391-397.

129 Bakker EN, van der Meulen ET, van den Berg BM, Everts V, Spaan JA, Vanbavel E: Inward remodeling follows chronic vasoconstriction in isolated resistance arteries. J Vasc Res 2002;39:12-20.

130 Bakker EN, Buus CL, Vanbavel E, Mulvany MJ: Activation of resistance arteries with endothelin-1: from vasoconstriction to functional adaptation and remodeling. J Vasc Res 2004;41:174-182.

131 Rizzoni D, Porteri E, Boari GE, De Ciuceis C, Sleiman I, Muiesan ML, Castellano M, Miclini M, Agabiti-Rosei E: Prognostic significance of small-artery structure in hypertension. Circulation 2003;108:22302235.

132 Mathiassen ON, Buus NH, Sihm I, Thybo NK, Morn B, Schroeder AP, Thygesen K, Aalkjaer C, Lederballe O, Mulvany MJ, Christensen KL: Small artery structure is an independent predictor of cardiovascular events in essential hypertension. J Hypertens 2007;25:1021-1026.

133 Langille BL, Bendeck MP, Keeley FW: Adaptations of carotid arteries of young and mature rabbits to reduced carotid blood flow. Am J Physiol 1989;256:H931-H939.

134 Rudic RD, Bucci M, Fulton D, Segal SS, Sessa WC: Temporal events underlying arterial remodeling after chronic flow reduction in mice: correlation of structural changes with a deficit in basal nitric oxide synthesis. Circ Res 2000;86:1160-1166.

135 Langille BL, O’Donnell F: Reductions in arterial diameter produced by chronic decreases in blood flow are endothelium-dependent. Science 1986;231:405-407.

136 Rudic RD, Shesely EG, Maeda N, Smithies O, Segal SS, Sessa WC: Direct evidence for the importance of endothelium-derived nitric oxide in vascular remodeling. J Clin Invest 1998;101:731-736.

137 Loufrani L, Levy BI, Henrion D: Defect in microvascular adaptation to chronic changes in blood flow in mice lacking the gene encoding for dystrophin. Circ Res 2002;91: 1183-1189.

138 Yamamoto K, Sokabe T, Matsumoto T, Yoshimura K, Shibata M, Ohura N, Fukuda T, Sato T, Sekine K, Kato S, Isshiki M, Fujita T, Kobayashi M, Kawamura K, Masuda H, Kamiya A, Ando J: Impaired flow-dependent control of vascular tone and remodeling in P2X4-deficient mice. Nat Med 2006;12: 133-137.

139 Martinez-Lemus LA, Hill MA, Meininger GA: The plastic nature of the vascular wall: a continuum of remodeling events contributing to control of arteriolar diameter and structure. Physiology (Bethesda) 2009;24: 45-57.
140 Wakatsuki T, Schwab B, Thompson NC, Elson EL: Effects of cytochalasin D and latrunculin $\mathrm{B}$ on mechanical properties of cells. J Cell Sci 2001;114:1025-1036.

141 Cipolla MJ, Osol G: Vascular smooth muscle actin cytoskeleton in cerebral artery forced dilatation. Stroke 1998;29:12231228.

142 Vanbavel E, Bakker EN, Pistea A, Sorop O, Spaan JA: Mechanics of microvascular remodeling. Clin Hemorheol Microcirc 2006; 34:35-41.

143 Bakker EN, Buus CL, Spaan JA, Perree J, Ganga A, Rolf TM, Sorop O, Bramsen LH, Mulvany MJ, Vanbavel E: Small artery remodeling depends on tissue-type transglutaminase. Circ Res 2005;96:119-126.

144 Bakker EN, Pistea A, Spaan JA, Rolf T, de Vries CJ, van Rooijen N, Candi E, Vanbavel E: Flow-dependent remodeling of small arteries in mice deficient for tissue-type transglutaminase: possible compensation by macrophage-derived factor XIII. Circ Res 2006;99:86-92.

145 Pistea A, Bakker EN, Spaan JA, Hardeman MR, van Rooijen N, Vanbavel E: Small artery remodeling and erythrocyte deformability in L-NAME-induced hypertension: role of transglutaminases. J Vasc Res 2008; 45:10-18.

146 Eftekhari A, Rahman A, Schaebel LH, Chen H, Rasmussen CV, Aalkjaer C, Buus CL, Mulvany MJ: Chronic cystamine treatment inhibits small artery remodelling in rats. J Vasc Res 2007;44:471-482.

147 Lukowski R, Weinmeister P, Bernhard D, Feil S, Gotthardt M, Herz J, Massberg S, Zernecke A, Weber C, Hofmann F, Feil R: Role of smooth muscle cGMP/cGKI signaling in murine vascular restenosis. Arterioscler Thromb Vasc Biol 2008;28:12441250.

148 Schaper W, Scholz D: Factors regulating arteriogenesis. Arterioscler Thromb Vasc Biol 2003;23:1143-1151.

149 van Royen N, Piek JJ, Buschmann I, Hoefer I, Voskuil M, Schaper W: Stimulation of arteriogenesis; a new concept for the treatment of arterial occlusive disease. Cardiovasc Res 2001;49:543-553.

150 Buschmann IR, Hoefer IE, van Royen N, Katzer E, Braun-Dulleaus R, Heil M, Kostin S, Bode C, Schaper W: GM-CSF: a strong arteriogenic factor acting by amplification of monocyte function. Atherosclerosis 2001;159:343-356.

151 van Weel V, Toes RE, Seghers L, Deckers MM, de Vries MR, Eilers PH, Sipkens J, Schepers A, Eefting D, van Hinsbergh VW, van Bockel JH, Quax PH: Natural killer cells and CD4+ T-cells modulate collateral artery development. Arterioscler Thromb Vasc Biol 2007;27:2310-2318. 
-152 Bakker EN, Matlung HL, Bonta P, de Vries CJ, van Rooijen N, Vanbavel E: Blood flowdependent arterial remodelling is facilitated by inflammation but directed by vascular tone. Cardiovasc Res 2008;78:341-348.

$\checkmark 153$ Cross JC, Hemberger M, Lu Y, Nozaki T, Whiteley K, Masutani M, Adamson SL: Trophoblast functions, angiogenesis and remodeling of the maternal vasculature in the placenta. Mol Cell Endocrinol 2002; 187:207-212.

- 154 Tabiasco J, Rabot M, Aguerre-Girr M, El Costa H, Berrebi A, Parant O, Laskarin G, Juretic K, Bensussan A, Rukavina D, Le Bouteiller P: Human decidual NK cells: unique phenotype and functional properties: a review. Placenta 2006;27(suppl A): S34-S39.

- 155 Ko EA, Amiri F, Pandey NR, Javeshghani D, Leibovitz E, Touyz RM, Schiffrin EL: Resistance artery remodeling in deoxycorticosterone acetate-salt hypertension is dependent on vascular inflammation: evidence from m-CSF-deficient mice. Am J Physiol Heart Circ Physiol 2007;292: H1789-H1795.

-156 De Ciuceis C, Amiri F, Brassard P, Endemann DH, Touyz RM, Schiffrin EL: Reduced vascular remodeling, endothelial dysfunction, and oxidative stress in resistance arteries of angiotensin II-infused macrophage colony-stimulating factor-deficient mice: evidence for a role in inflammation in angiotensin-induced vascular injury. Arterioscler Thromb Vasc Biol 2005; 25:2106-2113.

157 Bayliss WM: On the local reactions of the arterial wall to changes of internal pressure. J Physiol 1902;28:220-231.
158 Carlson BE, Arciero JC, Secomb TW: Theoretical model of blood flow autoregulation: roles of myogenic, shear-dependent, and metabolic responses. Am J Physiol Heart Circ Physiol 2008;295:H1572-H1579.

159 Jacobsen JC, Mulvany MJ, Holstein-Rathlou NH: A mechanism for arteriolar remodeling based on maintenance of smooth muscle cell activation. Am J Physiol Regul Integr Comp Physiol 2008;294:R1379R1389.

160 Hill MA, Zou H, Potocnik SJ, Meininger GA, Davis MJ: Invited review: arteriolar smooth muscle mechanotransduction: $\mathrm{Ca}(2+)$ signaling pathways underlying myogenic reactivity. J Appl Physiol 2001;91: 973-983.

161 Davis MJ, Wu X, Nurkiewicz TR, Kawasaki J, Davis GE, Hill MA, Meininger GA: Integrins and mechanotransduction of the vascular myogenic response. Am J Physiol Heart Circ Physiol 2001;280:H1427H1433.

162 Davis MJ, Hill MA: Signaling mechanisms underlying the vascular myogenic response. Physiol Rev 1999;79:387-423.

163 Hill MA, Sun Z, Martinez-Lemus L, Meininger GA: New technologies for dissecting the arteriolar myogenic response. Trends Pharmacol Sci 2007;28:308-315.

164 Schubert R, Lidington D, Bolz SS: The emerging role of $\mathrm{Ca}^{2+}$ sensitivity regulation in promoting myogenic vasoconstriction. Cardiovasc Res 2008;77:8-18.

165 Sonoyama K, Greenstein A, Price A, Khavandi $\mathrm{K}$, Heagerty $\mathrm{T}$ : Vascular remodeling implications for small artery function and target organ damage. Ther Adv Cardiovasc Dis 2007;1:129-137.
166 Spaan J, Kolyva C, van den Wijngaard J, ter Wee R, van Horssen P, Piek J, Siebes M: Coronary structure and perfusion in health and disease. Philos Transact A Math Phys Eng Sci 2008;366:3137-3153.

167 Dankelman J, Cornelissen AJ, Lagro J, Vanbavel E, Spaan JA: Relation between branching patterns and perfusion in stochastic generated coronary arterial trees. Med Biol Eng Comput 2007;45:25-34

168 Spaan JA, ter Wee R, van Teeffelen JW, Streekstra G, Siebes M, Kolyva C, Vink H, Fokkema DS, Vanbavel E: Visualisation of intramural coronary vasculature by an imaging cryomicrotome suggests compartmentalisation of myocardial perfusion areas. Med Biol Eng Comput 2005;43: 431-435.

169 Cornelissen AJ, Dankelman J, Vanbavel E, Spaan JA: Balance between myogenic, flowdependent, and metabolic flow control in coronary arterial tree: a model study. Am J Physiol Heart Circ Physiol 2002;282: H2224-H2237.

170 Cornelissen AJ, Dankelman J, Vanbavel E, Stassen HG, Spaan JA: Myogenic reactivity and resistance distribution in the coronary arterial tree: a model study. Am J Physiol Heart Circ Physiol 2000;278:H1490H1499.

171 Gleason RL, Humphrey JD: A mixture model of arterial growth and remodeling in hypertension: altered muscle tone and tissue turnover. J Vasc Res 2004;41:352-363.

172 Humphrey JD, Eberth JF, Dye WW, Gleason RL: Fundamental role of axial stress in compensatory adaptations by arteries. J Biomech 2009;42:1-8. 